\title{
Phylogeny and divergence times of suckers (Cypriniformes: Catostomidae) inferred from Bayesian total-evidence analyses of molecules, morphology, and fossils
}

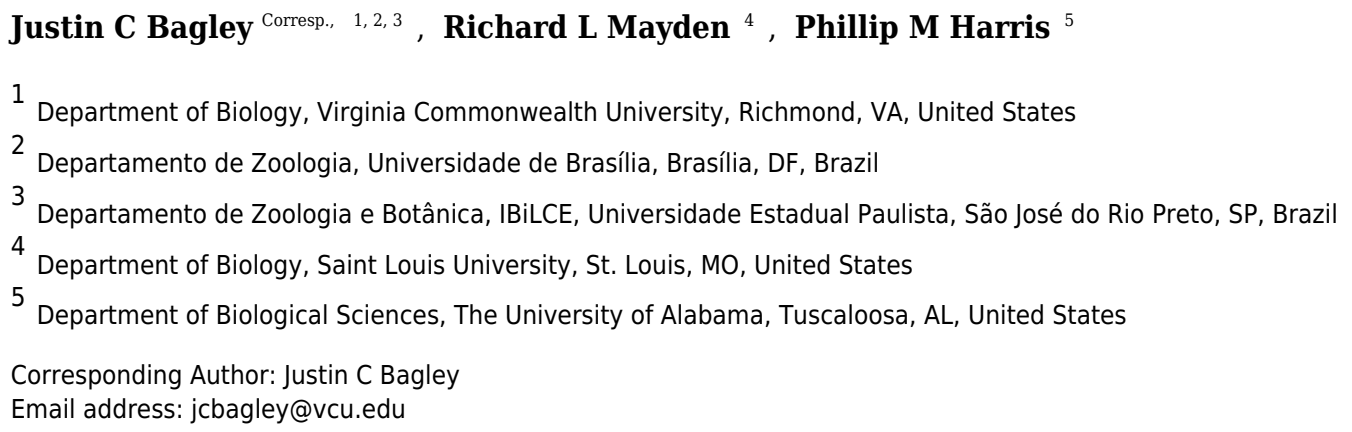

Catostomidae ('suckers') is a diverse (76 species) and broadly distributed family of Holarctic freshwater fishes with a rich fossil record and a considerable number ( $35 \%)$ of threatened and imperiled species. We integrate DNA sequences (three mitochondrial genes, three nuclear genes), morphological data, and fossil information to infer sucker phylogenetic relationships and divergence times using Bayesian 'total-evidence' methods, and then test hypotheses about the temporal diversification of the group. Our analyses resolved many nodes within subfamilies and clarified Catostominae relationships to be of the form ((Thoburniini, Moxostomatini), (Erimyzonini, Catostomini)). Patterns of subfamily relationships were incongruent, but mainly supported two placements of the Myxocyprininae; distinguishing these using Bayes factors lent strongest support to a model with Myxocyprininae sister to all remaining sucker lineages. We improved our Bayesian total-evidence dating analysis by excluding problematic characters, using a clockpartitioning scheme identified by Bayesian model selection, and employing a fossilized birth-death tree prior accommodating morphological data and fossils. The resulting chronogram showed that suckers evolved since the Late Cretaceous-Eocene, and that the Catostomini and Moxostomatini clades have accumulated species diversity since the early to mid-Miocene. These results agree with the fossil record and confirm previous hypotheses about dates for the origins of Catostomide and catostomine diversification, but reject previous molecular hypotheses about the timing of divergence of ictiobines, and between Asian-North American lineages. Overall, our findings from a synthesis of multiple data types enhance understanding of the phylogenetic relationships, taxonomic classification, and temporal diversification of suckers, while also highlighting practical methods for improving Bayesian divergence dating models by coupling phylogenetic 
informativeness profiling with relaxed-clock partitioning. 
1 Research Article

\section{Phylogeny and divergence times of suckers (Cypriniformes: Catostomidae) 3 inferred from Bayesian total-evidence analyses of molecules, morphology, and 4 fossils}

5 Justin C. Bagley ${ }^{1,2,3,{ }^{*}}$, Richard L. Mayden ${ }^{4}$, and Phillip M. Harris ${ }^{5}$

6 Author Addresses: ${ }^{1}$ Department of Biology, Virginia Commonwealth University, Richmond,

7 VA, USA; ${ }^{2}$ Departamento de Zoologia, Universidade de Brasília, Brasília, DF, Brazil;

$8 \quad{ }^{3}$ Departamento de Zoologia e Botânica, IBiLCE, Universidade Estadual Paulista, São José do

9 Rio Preto, SP, Brazil; ${ }^{4}$ Department of Biology, Saint Louis University, St. Louis, MO, USA;

$10{ }^{5}$ Department of Biological Sciences, The University of Alabama, Tuscaloosa, AL, USA

11 AuthorE-mail Addresses: JCB: jcbagley@vcu.edu; RLM: richard.mayden@slu.edu; PMH:

12 pharris@ua.edu.

13 *Corresponding author: Dr. Justin C. Bagley; Phone: +001 (804)-828-0820; Fax: +001 (804)-

14 828-0503; E-mail: jcbagley@vcu.edu.

15 Running head: Sucker phylogeny and divergence times (37 characters w/spaces)

18 Contents: $\sim 8,507$ words (Title, Abstract, main text, and Acknowledgements; excluding

19 References and table/figure captions); 4 tables; 5 figures. 


\section{Abstract}

21 Catostomidae ('suckers') is a diverse (76 species) and broadly distributed family of Holarctic

22 freshwater fishes with a rich fossil record and a considerable number $(\sim 35 \%)$ of threatened and

23 imperiled species. We integrate DNA sequences (three mitochondrial genes, three nuclear

24 genes), morphological data, and fossil information to infer sucker phylogenetic relationships and

25 divergence times using Bayesian 'total-evidence' methods, and then test hypotheses about the

26 temporal diversification of the group. Our analyses resolved many nodes within subfamilies and

27 clarified Catostominae relationships to be of the form ((Thoburniini, Moxostomatini),

28 (Erimyzonini, Catostomini)). Patterns of subfamily relationships were incongruent, but mainly

29 supported two placements of the Myxocyprininae; distinguishing these using Bayes factors lent

30 strongest support to a model with Myxocyprininae sister to all remaining sucker lineages. We

31 improved our Bayesian total-evidence dating analysis by excluding problematic characters, using

32 a clock-partitioning scheme identified by Bayesian model selection, and employing a fossilized

33 birth-death tree prior accommodating morphological data and fossils. The resulting chronogram

34 showed that suckers evolved since the Late Cretaceous-Eocene, and that the Catostomini and

35 Moxostomatini clades have accumulated species diversity since the early to mid-Miocene. These

36 results agree with the fossil record and confirm previous hypotheses about dates for the origins

37 of Catostomidae and catostomine diversification, but reject previous molecular hypotheses about

38 the timing of divergence of ictiobines, and between Asian-North American lineages. Overall,

39 our findings from a synthesis of multiple data types enhance understanding of the phylogenetic

40 relationships, taxonomic classification, and temporal diversification of suckers, while also

41 highlighting practical methods for improving Bayesian divergence dating models by coupling

42 phylogenetic informativeness profiling with relaxed-clock partitioning. 


\section{Introduction}

44 'Suckers' in the family Catostomidae (Cypriniformes) form a large family of Holarctic

45 freshwater fishes with 76 extant species in 14 genera native to North America and Asia (Harris et

46 al., 2014). Seventy-five species from 13 genera occur in North America (Harris et al., 2014;

47 Nelson et al., 2004; Unmack et al. 2014), where they constitute the third largest freshwater fish

48 clade, after darters (Etheostomatinae) and minnows (Cyprinidae), and $\sim 8 \%$ of the continental

49 ichthyofauna (Warren et al., 2000). Myxocyprinus asiaticus is endemic to eastern China and

50 Catostomus catostomus is the only extant trans-Pacific species (Harris et al., 2014). Suckers are

51 an ancient group whose fossil record spans the Cenozoic, from the early Eocene onwards

52 (Cavender, 1986; Smith, 1992; Smith et al., 2002; Appendix S1). Around 35\% of the taxa (26 to

$53>35$ species or genetic lineages) are endangered, threatened, or of special conservation concern

54 (Harris et al., 2014; Nelson et al., 2004; Warren et al., 2000).

55 Geographical distributions of suckers and their taxonomy and relationships have attracted

56 the interest of systematists and biogeographers for over 150 years (e.g. Agassiz, 1854). Pre-1900

57 systematics and taxonomy studies dealt with species descriptions and higher-level classifications

58 of the group (reviewed by Harris et al., 2014; Smith, 1992). Subsequently, key papers on sucker

59 classification designated genera, subgenera, and tribes (Hubbs, 1930; Robins \& Raney, 1956)

60 and contributed a pre-cladistics phylogeny (Miller, 1959), as well as the first phylogeny for

61 species in the tribe Moxostomatini (Jenkins, 1970). The findings of post-systematics studies of

62 sucker interrelationships (last 40 years), which were based on a variety of different data types,

63 are summarized in Table 1 and Figure 1. These studies supported the recognition of four

64 subfamilies (Myxocyprininae, Cycleptinae, Ictiobinae, and Catostominae) and tribes

65 (Catostomini, Erimyzonini, Moxostomatini, Thoburniini) plus the modern allocation of genera to

66 these groups (Harris \& Mayden, 2001; Harris et al., 2002). Most phylogenetic analyses of 
67 suckers to date have analyzed DNA sequence data from increasing numbers of mitochondrial

68 DNA (mtDNA) or nuclear DNA (nDNA) genes. Recent advances include Clements et al.'s

69 (2012) study of phylogenetic relationships of Moxostomatini using the first dataset based on two

70 loci-mtDNA cyt $b$ and nuclear growth hormone intron (GHI) sequences. Also, Unmack et al.

71 (2014) studied the phylogeny and biogeography of Pantosteus, a former subgenus of Catostomus

72 (Harris \& Mayden, 2001; Harris et al., 2002; Smith, 1966) using independent morphological and

73 mtDNA genetic analyses. Overall, while the inclusion of additional taxa and sequence data in

74 recent analyses has yielded novel insights on sucker relationships, a consensus among

75 hypotheses regarding relationships of higher-level species groups, i.e. subfamilies, has yet to

76 emerge (Table 1; Fig. 1). Moreover, although time-calibrated phylogenies based on

77 comprehensive tip sampling are necessary to understand the tempo and mode of diversification

78 of groups of freshwater fishes (e.g. Near et al., 2011, 2012), such a tool has yet to be inferred for

79 suckers. This leaves workers at a distinct disadvantage in considering the macroevolutionary,

80 ecological, or conservation trends of suckers in a phylogenetic context.

81 In this study, we use 'total-evidence' analyses of multilocus sequence data from three

82 mtDNA genes and three nuclear genes representing the most comprehensive sampling of suckers

83 to date, combined with available morphological and fossil data, to infer the phylogenetic

84 relationships and divergence times of suckers in a Bayesian framework. We discuss the

85 phylogenetic and taxonomic implications of our results in light of previous phylogenetic studies

86 of suckers. We apply Bayesian divergence time methods to the data (e.g. Drummond et al., 2012)

87 and take advantage of rich information on the age and distributions of sucker fossils (e.g.

88 Cavender, 1986; Smith et al., 2002; Appendix S1) to improve divergence time estimation by

89 incorporating extant and fossil sampling in a "fossilized birth-death process" tree prior (Stadler 
90 2010; Gavryushkina et al., 2014; Heath et al. 2014). Moreover, by coupling assessments of the

91 phylogenetic signal of different data subsets with evaluation of clock-partitioning strategies, we

92 were able to avoid potentially confounding effects of problematic characters on our divergence

93 time inferences. The resulting time-calibrated phylogeny is then used to test several hypotheses

94 about the temporal diversification of suckers. Namely, we test the hypotheses $\left(H_{1}\right)$ that Asian

95 Myxocyprininae and North American suckers (Cycleptinae) diverged since $\sim 14$ million years

96 ago $(\mathrm{Ma})$ in the mid-Miocene, and $\left(\mathrm{H}_{2}\right)$ that the initial divergence of Ictiobinae lineages occurred

97 since $\sim 10 \mathrm{Ma}$ in the late Miocene, as indicated by mtDNA cyt $b$ gene divergences (Sun et al.,

98 2007). We also tested the hypotheses $\left(\mathrm{H}_{3}\right)$ that the diversification of lineages within

99 Catostominae followed $\sim 20 \mathrm{Ma}$ in the Miocene (Smith, 1992; Sun et al., 2007), and $\left(H_{4}\right)$ that

100 Catostomidae species have diversified from a tetraploid ancestor since $\sim 50 \mathrm{Ma}$ in the early

101 Eocene (Uyeno \& Smith, 1972). Overall, by yielding a new phylogeny of suckers and divergence

102 dates for their most recent common ancestors (MRCAs), our study sheds light on the

103 interrelationships, taxonomic classification, and tempo of speciation in a diverse and threatened

104 clade of Holarctic freshwater fishes.

105 Materials \& Methods

106 Molecular taxon sampling, laboratory methods, and sequence alignment

107 We obtained and sequenced mtDNA and nDNA genes from tissue samples of 121 sucker

108 specimens from throughout the geographical range of the family. Samples were provided by

109 ichthyological collections or colleagues (see Acknowledgements), or were already in-hand at the

110 beginning of the study. We sequenced taxa representing all sucker genera and all Catostominae

111 species except for $\uparrow$ Moxostoma lacerum, an historically extinct taxon last sampled from the

112 Mississippi River Basin in 1893 (NatureServe, 2013), and Chasmistes cujus, an endangered 
113 species (NatureServe, 2014) for which it was difficult to obtain samples (Table 2). To

114 complement our sampling and add data from more unlinked loci to our datasets, we obtained

115 additional sequences from GenBank as described below. Overall, we obtained genetic sequences

116 for the most comprehensive taxonomic sampling of the family to date, including 78

117 species/lineages representing all 14 extant genera, including four 'candidate species' within

118 Moxostomatini (Table 2). Based on recent hypotheses of relationships of suckers and

119 cypriniform fishes (e.g. Mayden et al., 2008; Saitoh et al., 2006; Smith, 1992), we included DNA

120 sequences from five outgroup taxa in our datasets: Cyprinus carpio (Cyprinidae); Gyrinocheilus

121 aymonieri (Gyrinocheilidae); and Cobitis striata, Chromobotia macracanthus, and Leptobotia

122 mantschurica (Cobitidae). We follow the taxonomy of subfamilies listed in Harris and Mayden

123 (2001) and Harris et al. (2002).

124 All molecular laboratory work for this project conducted in the R. L. Mayden laboratory

125 was approved under Saint Louis University Institutional Animal Care and Use Committee

126 (IACUC) protocol \#2467. We extracted whole genomic DNA using QIAGEN DNeasy Tissue

127 kits (QIAGEN, Valencia, CA, Catalog No. 69506), or the CTAB method of Sagahi-Maroof et al.

128 (1984). We amplified and sequenced the mtDNA cytb gene using PCR primers and parameters

129 in Harris et al. (2002). We amplified and sequenced the mtDNA NADH subunit 2 (ND2) gene

130 with primers 562 (5'-TAA GCT ATC GGG CCC ATA CC-3') and 449 (5'-TGC TTA GGG CTT

131 TGA AGG CTC-3') from LGL Genetics, Bryan, TX, using the same PCR amplification

132 parameters used for cytb. We also sequenced the first part of the nuclear IRBP gene using PCR

133 primers and methods in Chen et al. (2008), and we sequenced nuclear ribosomal protein $S 7$

134 intron 1 (RPS7) using PCR primers and parameters in Chow \& Takeyama (1998). We purified

135 double-stranded PCR products using columns or gel extraction kits (QIAGEN, Valencia, CA). 
136 Given that catostomids are tetraploids (Uyeno \& Smith, 1972), we cloned nuclear PCR products

137 to ensure orthologous sequences were used in subsequent phylogenetic reconstructions. Purified

138 PCR products were cloned using the TOPO TA Cloning® Kit (Invitrogen Corp., Carlsbad, CA)

139 with TOP10 chemically competent or electrocompetent cells. Positive colonies were chosen

140 randomly and cultured, and then plasmids preps were purified using the QIAprep Spin Miniprep

141 Kit (QIAGEN, Valencia, CA) and sequenced in both directions using universal M13 primers. We

142 sequenced all genes in both directions on an Applied Biosystems 3100 Genetic Analyzer using

143 ABI PRISM BigDye Terminator v2.0 or v3.0 Cycle Sequencing Kits (Applied Biosystems,

144 Foster City, CA).

145 We edited sequence chromatographs, assembled sequence contigs, and created final DNA

146 alignments using Geneious v5.4 (Kearse et al., 2012). We translated all gene sequences into

147 amino acid sequences to check alignments for stop codons or elevated nonsynonymous

148 substitution numbers, because these signatures can indicate the presence of nuclear mtDNA gene

149 copies, or 'NUMTs'. Mitochondrial DNA and IRBP sequences aligned straightforwardly ‘by-

150 eye' in Geneious. However, we aligned nuclear RPS7 sequences, and nuclear genes from other

151 studies listed below, in MAFFT v6.850 (Katoh \& Toh, 2008) using the local-pair FFTS

152 algorithm with MAXITERATE $=50$.

153 Dataset construction, model selection, and Bayesian phylogenetic analyses

154 We collated seven datasets for our analyses that we describe here, and which correspond 155 sequentially to datasets listed in Table 3 and trees shown in Figs. 2A-G (see Results). (1) The

156 'concatenated mtDNA' dataset consisted of mtDNA cyt $b$ and ND2 sequences for 126 tips (121

157 sucker samples and 5 outgroup samples) plus 58 mtDNA cytochrome oxidase subunit 1 (coxl)

158 gene sequences from GenBank. (2) A 'four-locus' DNA dataset with the same 126 tips but 
159 adding the following nuclear data to the concatenated mtDNA dataset: $44 \mathrm{GHI}$ sequences from

160 Clements et al. (2012) and GenBank, plus 113 IRBP sequences and 52 RPS7 sequences from our

161 study. (3) We reanalyzed a morphological dataset first presented by Smith (1992), containing

162123 morphological characters for 64 taxa including 62 sucker taxa and two outgroup taxa. This

163 matrix contained two extinct taxa: the historically extinct $\uparrow$ M. lacerum, and $\uparrow$ Amyzon, an

164 Eocene-Oligocene genus of fossil suckers composed of five valid species known from British

165 Columbia, Washington, Nevada, and Wyoming (four species), and Jilin province, China (Bruner,

166 1991; Chang et al., 2001; Smith, 1992; Appendix S1). (4) The fourth 'mtDNA + morphology'

167 dataset combined datasets 1 and 3. (5) Our 'total-evidence' dataset contained all morphological

168 and molecular characters analyzed in this study, for 85 taxa. Two final nDNA datasets were: (6)

169 a 'nuclear IRBP' alignment for the only nuclear gene with complete sampling, and (7) a

170 'concatenated nDNA' alignment containing all three nuclear loci. Overall, the morphology

171 dataset was analyzed alone (dataset 3; see Results Fig. 2C), in concert with mtDNA genes

172 (dataset 4; see Results Fig. 2D), and combined with the full DNA sequence dataset in total-

173 evidence analyses of dataset 5 (e.g. see Results Fig. 2E).

174 We selected the most appropriate partitioning schemes and models of sequence evolution

175 for each of the DNA data 'subsets' or 'blocks' used in our phylogenetic analyses in

176 PartitionFinder v1.1.1 (Lanfear et al., 2012), which included codon positions of the mtDNA and

177 IRBP alignments, plus the GHI and RPS7 genes. We ran PartitionFinder simultaneously on all

178 initial DNA subsets using the greedy heuristic search algorithm, which we set to conduct model

179 comparisons to determine the 'best-fit' partitioning scheme based on the Bayesian information

180 criterion (BIC). PartitionFinder relies heavily on PhyML, which we set to link branch lengths,

181 search 56 substitution models, and estimate the base frequencies, proportion of invariant sites $(I)$, 
182 and the gamma shape distribution $(\Gamma)$ of each model using maximum-likelihood.

183 We performed partitioned Bayesian phylogenetic analyses on all seven datasets in

184 MrBayes 3.2.2 (Ronquist et al., 2012). Analyzing different taxon and character combinations

185 allowed us to evaluate the effect of different data types, and of including morphological data and

186 extinct taxa, on phylogenetic analyses of suckers. During molecular analyses, we specified

187 partitioning schemes and best-fit models of sequence evolution selected in PartitionFinder,

188 except where the selected model was not implemented in MrBayes we used the next most closely

189 related model in the GTR family of models. Given that rate variation among morphological

190 characters can confound phylogenetic branch lengths, applying $\Gamma$-distributed rates can greatly

191 improve models of morphological evolution (e.g. Clarke \& Middleton, 2008). Thus, for the

192 morphological analysis, we specified Lewis's (2001) Markov variable (Mkv) model with $\Gamma$ -

193 distributed rate heterogeneity and left characters unordered in state polarity (default). For each

194 dataset, we conducted three independent MrBayes runs of eight chains, each with a Markov

195 chain Monte Carlo (MCMC) chain length of 50 million generations. We diagnosed run

196 convergence using the potential scale reduction factor, which should approach values of 1 when

197 stationarity has been reached (Ronquist et al., 2012).

198 Bayesian total-evidence dating and relaxed-clock partitioning

199 We estimated divergence times as times to the most recent common ancestor $\left(t_{\mathrm{MRCA}} \mathrm{S}\right)$ through

200 Bayesian relaxed molecular clock analyses of the total-evidence dataset in BEAST v2.4.5

201 (Bouckaert et al., 2014). For our tree prior, we employed the fossilized birth-death (FBD)

202 process model (Gavryushkina et al., 2014; Heath et al., 2014) as modified by Gavryushkina et al.

203 (2017), because this model accommodates total-evidence datasets, avoids the need for arbitrary

204 calibration densities, and accommodates all fossils available for a group, and not merely ad hoc 
205 selections. In addition to 83 extant ingroup and outgroup samples, 19 extinct sucker taxa and

206 their available minimum ages from the fossil record were included in the BEAST analyses based

207 on evidence provided in Appendix S1. We calculated the approximate sampling proportion for

208 extant lineages ( $\rho)$ as 0.97 and set the FBD time of origin prior $\left(t_{\mathrm{or}}\right)$ to the Cypriniformes 'Root'

209 node calibration discussed in Appendix S1. Morphological characters were partitioned into

210 groups having the same number of states, and each partition was assigned an Mkv model (Lewis,

2112001 ; conditioning on the use of only variable characters) with $\Gamma$-distributed rate variation

212 ("partitioned mode" in Gavryushkina et al., 2017). We partitioned the DNA data and set site

213 models according to the best scheme identified in PartitionFinder. Other authors have employed

214 FBD models on a fixed topology (e.g. Heath et al., 2014) or simultaneously estimated topology

215 and FBD parameters (e.g. Gavryushkina et al., 2017). We allowed most nodes, including

216 subfamily relationships, to change freely. However, we constrained the Catostomini and

217 Moxostomatini crown groups to be monophyletic, consistent with our MrBayes results and

218 hypotheses of previous studies (see Results and Discussion sections). Posterior nodal support can

219 be markedly weakened when fossils have unscored characters (e.g. Gavryushkina et al., 2017) or

220 lack data. To avoid spurious relationships arising from the large proportion of fossil Ictiobinae

221 taxa (57\%) and Myxocyprininae taxa (50\%) lacking data, samples of Carpiodes, Ictiobus,

222 Ictiobinae, and Myxocyprininae were each constrained to be monophyletic, consistent with our 223 other phylogenetic results.

224 According to Ho \& Lanfear (2010), implementing multiple relaxed-clock models for

225 different data subsets in a data-partitioning scheme can provide a more biologically realistic way

226 to model among-lineage rate variation and improves the fit of relaxed-clock models to the data.

227 Using a relaxed-clock partitioning scheme may also yield more precise date estimates with 
228

229

230

231

232

233

234 235

narrower credible intervals (Ho \& Lanfear, 2010). We statistically tested whether allocating separate uncorrelated lognormal relaxed clocks to different DNA data subsets, through 'relaxedclock partitioning', yielded divergence time estimation models that provided a better fit to the data than assuming a single model of branch-specific rates across all data subsets. First, we estimated divergence dates and marginal likelihood scores for each of 12 different relaxed-clock partitioning models $\left(M_{1}-M_{12}\right)$ with one to eight clocks (see Results and Discussion). Second, we estimated Bayes factors and conducted Bayesian model selection to identify the best-supported model.

We ran five replicate searches of each model in BEAST $\left(\mathrm{MCMC}=2 \times 10^{7}\right.$ generations, sampling every 4000) using the 'BEASTRunner.sh' script in PIrANHA (Bagley, 2017). We then estimated log-marginal likelihoods for each model by conducting path sampling (PS) (Baele et al., 2012) for 100 steps $\left(10^{6}\right.$ generations each), while specifying a $\sim B(0.3,1)$ distribution for spacing the path steps (Xie et al., 2011). We calculated $2 \log _{e}\left(B_{10}\right)$ Bayes factors from the logmarginal likelihoods and evaluated 'weight of evidence' of the models according to criteria in Kass \& Raftery (1995). We took posterior distributions from the best-supported model as our best estimates of the time tree and divergence dates for Catostomidae lineages. We summarized parameters from the best-supported model, and ensured convergence and adequate effective sample sizes (ESS >100-200), using Tracer v1.5 (Rambaut \& Drummond, 2014). We calculated a maximum clade credibility tree annotated with mean node ages from 5,000 post-burn-in trees in TreeAnnotator v2.4.5.

\section{Using phylogenetic informativeness profiles to exclude problematic characters}

Among other factors influencing phylogenetic inference, such as sampling effects on branch lengths or nodal support values (e.g. Heath et al., 2008; Pyron, 2011), the varying 
251 informativeness of different character sets can substantially and adversely affect phylogenetic

252 divergence dating results (Dornburg et al., 2014). Fortunately, recent methods for quantifying

253 and visualizing 'phylogenetic informativeness' (PI) profiles of character sets through time

254 (Townsend, 2007; Townsend et al., 2012) provide a framework for identifying and excluding

255 problematic character sets (Dornburg et al., 2014). One common pitfall is the use of characters

256 whose profiles exhibit a decline in informativeness towards the root. As noted by Townsend \&

257 Leuenberger (2011), this decline marks a "rain shadow of noise", with the corresponding dataset

258 losing phylogenetic informativeness due to an increase in predicted homoplasy. In turn,

259 homoplasious loci or character sets, but especially mtDNA datasets exhibiting high saturation or

260 rootward declines in PI, have been shown to mislead global branch length values during

261 divergence time estimation (e.g. Brandley et al., 2011; Dornburg et al., 2014).

262 To identify and exclude potentially problematic character sets in our database, and to

263 evaluate whether support versus instability of subfamily relationships correlated to statistical

264 power to revolve branching order, we evaluated the Townsend (2007) PI and resolution

265 probabilities of each character set through time using PhyDesign (López-Giráldez \& Townsend,

266 2011). Estimating PI requires prior information on evolutionary-genetic rates and phylogeny.

267 Thus, we estimated rates for DNA characters and morphological characters using HyPhy (Pond

268 et al., 2005) and BayesTraits (Pagel \& Meade, 2014), respectively, and ran analyses along the

269 BEAST time tree from the best-supported clock-partitioning model (see Results and Discussion).

270 We estimated net PI for all eight data subsets in Table 3 during the 'subfamily divergence epoch'

271 spanning branches leading to Myxocyprininae, Cycleptinae, Ictiobinae, and Catostominae. These

272 analyses permitted broad comparisons of signal in the mitochondrial versus nuclear data, and

273 molecular versus morphological character sets. We excluded character sets that exhibited steep 
274 declines in PI towards the root of our phylogeny from the final divergence time results presented

275 below. We compared three resolution probabilities, including probability correct, probability

276 polytomy, and probability incorrect or 'phylogenetic noise' (equations 11-13 in Townsend et al.,

277 2012) for the excluded subsets versus other molecular subsets over the subfamily divergence

278 epoch. We also evaluated sensitivity of resolution probability approximations to varying the

279 internode time length $\left(t_{0}\right)$ parameter, by recalculating over $10 t_{0}$ values representing declining

280 fractions of the epoch.

\section{Results}

\section{Dataset characteristics and DNA substitution models}

283 Our final data matrices ranged in size from 123 characters in the morphological dataset to 6048

284 molecular and morphological characters in the total-evidence dataset (Table 3). Proportions of

285 missing data and parsimony informative characters ranged from $0.3-36.4 \%$ and from 21.9

$28697.6 \%$, respectively, across datasets (Table 3). PartitionFinder identified seven unique DNA

287 sequence subsets (scheme $\mathrm{BIC}=141854.71523)$, and the best-fit DNA substitution model for

288 each subset is listed in Table S1. Morphological character subsets (in subset M) were assigned

$289 \mathrm{Mkv}+\Gamma$ models, as described above. None of the mtDNA genes sequenced in this study showed

290 signs of NUMTs, and we found no indels in the IRBP sequences; however, GHI and RPS7 genes

291 aligned with $\sim 32$ and $\sim 16$ ingroup indels/gaps, respectively. We archived our sequence

292 alignments and phylogenetic tree results in Mendeley Data (doi: 10.17632/trw6sb4v7w.1).

293 Phylogenetic relationships among sucker subfamilies

294 We placed subfamilies Myxocyprininae and Cycleptinae as sister lineages in most trees, but with

295 higher posterior support [Bayesian posterior probability $(\mathrm{BPP})=0.74-0.99]$ in runs based largely

296 on mtDNA-encoded genes (Figs. 2A, 2D, S1 and S2) and weak BPP support $(\leq 0.69)$ in other 
297 runs (Figs. 2C, 2E, 3, S3). Frequently, when this pattern was obtained, Myxocyprininae +

298 Cycleptinae was resolved as sister to a monophyletic Ictiobinae with variable posterior support

299 (BPP = 0.69-0.98; Figs. 2, 3, S1 and S2). This 'subfamily pattern 1', with ((Myxocyprininae,

300 Cycleptinae), Ictiobinae), departs markedly from the placement of Ictiobinae sister to

301 Cycleptinae (sometimes including Myxocyprinus) + Catostominae in previous analyses of

302 morphology (Smith, 1992) and molecular data (Doosey et al., 2010; Harris \& Mayden, 2001;

303 Mayden et al., 2008; Saitoh et al., 2006). By contrast, several trees agreed in placing

304 Myxocyprininae as sister to all other sucker lineages, which agrees with previous mtDNA results

305 presented in Harris \& Mayden (2001). This 'subfamily pattern 2' relationship was strongly

306 supported with BPP = 1 in our total-evidence consensus topology from BEAST (Fig. 4) and

307 resolved with low support in the four-locus topology (Figs. 2B and S4). Distinguishing between

308 these two conflicting sets of subfamily relationships is difficult, because each is supported by

309 molecular and total-evidence topologies herein and agrees with at least one previous molecular

310 study. To objectively determine the arrangement of these subfamilies with the greatest weight of

311 evidence conditional on our total-evidence dataset, we compared subfamily patterns 1 and 2

312 using Bayes factors. We ran MrBayes as described above, except employing topological

313 constraints set to subfamily pattern 2, and then used stepping-stone sampling (Xie et al., 2011;

314 Baele et al., 2012) to estimate the log-marginal likelihoods of the models, from which Bayes

315 factor tests were conducted through comparisons to the unconstrained model matching subfamily

316 pattern 1 . Conducting 50,000 generations of stepping-stone sampling (sampling every 2500

317 generations) during each of 50 steps produced a total of 250,000 MCMC generations for

318 marginal likelihood estimation. The subfamily pattern 2 model constraining Myxocyprininae as

319 sister to all other suckers had a higher log-marginal likelihood score (-68390.83) than the 
320 unconstrained subfamily pattern 1 model $(-68910.88)$, and a $2 \log _{e}\left(B_{10}\right)$ Bayes factor of -1040.10

321 provided definitive weight of evidence against the unconstrained model.

322 Relationships of early-diverging sucker genera

323 We found that the early-diverging sucker genera Myxocyprinus, Cycleptus, Carpiodes, and

324 Ictiobus formed well-supported clades in most analyses. However, Ictiobus relationships were

325 resolved in a polytomy in our analysis of the concatenated mtDNA dataset (Fig. S1). In several

326 other trees, including those based on our total-evidence and mtDNA + morphology datasets

327 (Figs. 3 and S2), the Ictiobus clade received weak BPP support and eventually collapses into a

328 paraphyletic grade. In the analysis of the four-locus dataset with higher numerical sampling in

329 this clade, I. bubalus and I. niger relationships had high BPP support (BPP =0.94-1) but were

330 para-/polyphyletic, leaving their relationship to I. cyprinellus uncertain (Fig. S4).

331 Phylogenetic relationships among the Catostominae

332 Within the largest sucker subfamily, Catostominae, we consistently resolved clades with the

333 tribes Thoburniini + Moxostomatini and Erimyzonini + Catostomini across analyses. Our more

334 robust, multilocus and total-evidence trees resolved these relationships with definitive support

335 values of BPP $=0.99-1$. Within the Thoburniini + Moxostomatini clade, we consistently inferred

336 the genus Thoburnia to be paraphyletic, with T. atripinnis sister to a clade containing the three

337 Hypentelium species (mostly BPP $=1$ ). The sole exception to this was that our morphology tree

338 resolved Thoburnia as monophyletic with T. atripinnis sister to all other Thoburnia with strong

339 support $(\mathrm{BPP}=1)$. Within the Hypentelium clade, we inferred an identical and strongly

340 supported set of relationships of the form (H. roanokense, (H. etowanum, H. nigricans)) in the

341 mtDNA, four-locus, nDNA, and total-evidence gene trees (Figs. 3, S1, S2, S4 and S5). We

342 obtained the same set of relationships in our morphology analysis, but with weak $(\mathrm{BPP}=0.69)$ 
343 support for the H. etowanum-H. nigricans node (Fig. S3). We resolved Moxostoma as

344 monophyletic with BPP $=0.89-1$, except for a paraphyletic pattern in the morphology consensus

345 tree. Within the Erimyzonini, Erimyzon was monophyletic $(\mathrm{BPP}=1)$ and sister to Minytrema

346 (e.g. Fig. 3). None of the molecular or total-evidence topologies we inferred resolved

347 Catostomus as monophyletic relative to Chasmistes, Deltistes, or Xyrauchen. Here, yet again,

348 results from the morphology tree departed from our other results, failing to resolve relationships

349 among these or virtually any other catostomine lineages with strong support (Figs. 1C and S3).

350 As a result, we do not discuss the morphology consensus topology further in this section.

351 Relationships within the Erimyzonini and Catostomini were similar to those in previous

352 molecular studies (e.g. Harris et al., 2002; Doosey et al., 2010). Within Erimyzon, our results

353 placed E. sucetta rather than E. oblongus as sister to E. tenuis. Within Catostomini, we

354 consistently resolved 9 well-supported major clades within Catostominae (e.g. Figs. 3, S1 and

355 S4). Although relationships among these clades received varying posterior support, the species

356 groups we identified were highly supported in multiple analyses and provide more tenable

357 phylogenetic hypotheses than previously proposed for this tribe (Smith, 1992; Smith et al.,

358 2002). 'Clade 4' corresponded to a monophyletic Erimyzonini, while clades 5 through 9 included

359 various Catostomini subclades composed largely of Catostomus samples. For conciseness, we

360 provide an in-depth assessment of relationships only within 'Clade 5', whose results have the

361 most important phylogenetic and taxonomic implications. More granular presentation and

362 discussion of relationships within and among Catostomini clades 1-3 and 5-9 is provided at the

363 end of Appendix S1. 'Clade 5' corresponded mostly to the genus Pantosteus (Unmack et al.

364 2014) and was sister to the remaining Catostomini. Within Clade 5, we consistently resolved $P$.

365 nebuliferus $+P$. plebeius as sister to a clade containing all remaining Pantosteus, with $(P$. 
366 platyrhynchus, (P. santaanae, (P. clarkii, (P. d. discobolus, P. d. yarrowi)))) (e.g. Fig. 3).

367 Alternative topologies inferred for this clade involved rearrangements placing $P$. santaanae sister

368 to P. clarkii, but with non-significant posterior support (e.g. Figs. S1 and S4).

369 Bayesian total-evidence dating and relaxed-clock partitioning

370 Bayes factor comparisons of 12 clock-partitioning models showed that removing mtDNA $1^{\text {st }}$ and

$3713^{\text {rd }}$ codon sites deemed to be problematic during PI profiling (see below) progressively improved

372 model log-marginal likelihoods and posterior evidence (Table 4). For example, codon-partitioned

373 relaxed-clock models were overwhelmingly supported over simpler models allocating a single

374 relaxed clock to all data subsets, or all DNA subsets. The most complex model allocating relaxed

375 clocks to each data subset but including only mtDNA $2^{\text {nd }}$ positions, $M_{12}$, was decisively

376 supported as the best model. Compared with this model, other subset and clock schemes

377 produced negative improvements to the model, indicated by negative log Bayes factors;

378 however, the second best model separated DNA from morphological data subsets, consistent

379 with a decoupling of molecular rates from morphological rates (Table 4). Independent runs of the

380 best-supported BEAST model achieved ESS scores of $>100-200$ for all parameters and

381 converged on similar phylogeny and parameter estimates including mean and $95 \%$ highest

382 posterior densities (HPDs; i.e. credible intervals) for sucker $t_{\mathrm{MRCA}} \mathrm{s}$. For example, the posterior

383 ESS of the best model was 463 and that for the FBD model was 134 . The only exception to this

384 was the tMRCA for Moxostomatini, which received ESS scores between 72 and 89. Clocks on

385 different data subsets exhibited substantial among-lineage rate heterogeneity, with posterior

386 means and 95\% HPD intervals of the 'ucldStdev' (uncorrelated lognormal relaxed clock standard

387 deviation) and 'coefficientOfVariation' (coefficient of variation of branch-specific rates)

388 statistics excluding zero (Fig. S7); thus, relaxed-clock models were warranted by the data. 
390 of all suckers was 63.16 Ma in the Late Cretaceous, with credible intervals ranging from Late

391 Cretaceous to the Paleocene-Eocene boundary (95\% HPD: [54.02, 74.6]; Fig. 4). The four

392 sucker subfamilies had variable posterior age estimates ranging approximately an order of

393 magnitude. The Cycleptinae had the youngest posterior age estimate of 5.07 Ma in the Pliocene

394 (95\% HPD: $[0.87,10.23])$. Following their Late Cretaceous origin based on a stem age

395 corresponding to the MRCA of all suckers, the posterior $t_{\mathrm{MRCA}}$ estimate for Myxocyprininae

396 dated their diversification to $42.27 \mathrm{Ma}$ in the early to mid-Eocene (95\% HPD: [39.67, 54.58]).

397 Subsequently, Catostominae species diversified since an intermediate posterior age of $34.37 \mathrm{Ma}$

398 near the Eocene-Oligocene boundary (95\% HPD: [25.54, 42.77]), and Ictiobinae species had the

399 oldest posterior age estimate, dating to $49.69 \mathrm{Ma}$ in the early Eocene (95\% HPD: [48.88, 52.52]).

400 The catostomine tribes diverged approximately 29.87 Ma in the Oligocene (Catostomini +

401 Erimyzonini) and 20.78 Ma in the early Miocene (Moxostomatini + Thoburniini). The genera

402 Catostomus and Moxostoma, which correspond to tribes Catostomini and Moxostomatini,

403 diversified since 17.65 Ma and 15.25 Ma ago in the early-mid Miocene, respectively (Fig. 4).

\section{Phylogenetic informativeness profiles}

405 We evaluated potential impacts of phylogenetic signal on incongruent subfamily relationships by

406 estimating resolution probabilities, over the subfamily divergence epoch ( 63.2-34.4 Ma)

407 spanning the divergence of sucker subfamilies. Overall, mtDNA $1^{\text {st }}$ and $3^{\text {rd }}$ codon position data

408 subsets exhibited among the highest PI values, but with distinct Miocene peaks followed by

409 declining PI towards the root (Fig. 5). This suggested a prominent loss of evolutionary

410 information due to homoplasy; therefore, we excluded these sites from final divergence dating

411 analyses, in order to avoid potentially negative effects on the topology and time-calibrated 
412 branch lengths (Dornburg et al., 2014). All other molecular data subsets had substantial and

413 relatively constant predicted PI decaying over Paleocene or Eocene to present (recent spikes are

414 anomalies; Townsend et al. 2008). Morphological characters had slightly higher signal than

415 IRBP sites and exhibited stability before decaying 20 Ma to present (Fig. 5). In addition to nearly

416 constant net PI (Fig. 5), the retained character subsets also had low probabilities of phylogenetic

417 noise or polytomies, with notable increases in the probability of an incorrect topology only for

418 internode distances less than $\sim 0.35\left(t_{0}\right)$, or $<10.0$ million years (Myr) (Fig. S9).

\section{Discussion}

421 Sucker phylogeny and incongruence of subfamily lineages

422 Our phylogenetic reconstructions of Catostomidae relationships are similar to several previous

423 morphological and molecular studies. For example, others have hypothesized that Catostomidae

424 is monophyletic in studies focusing on suckers (e.g. Doosey et al., 2010; Ferris \& Whitt, 1978;

425 Harris \& Mayden, 2001; Smith, 1992; Fig. 1) and taxonomically broader analyses (e.g. Mayden

426 et al., 2008; Saitoh et al., 2006). Our finding that the four currently recognized sucker

427 subfamilies are monophyletic with definitive support also agrees with earlier phylogenetic

428 studies based on morphology (Smith, 1992) and molecules (Chen \& Mayden, 2012; Clements et

429 al., 2012; Doosey et al., 2010; Harris and Mayden, 2001; Harris et al., 2002; Sun et al., 2007).

430 This is perhaps unsurprising, as we reanalyzed previous morphological and molecular datasets

431 alongside new sequence data. Yet, ours are the first results definitively supporting patterns of

432 monophyly at the family and subfamily levels based on dense taxonomic sampling of mtDNA

433 and nuclear gene sequences for all sucker genera and most species, plus total-evidence analyses,

434 with BPP at or near 1 across datasets (Figs. 2, 3, and S1-S6). 

encountered difficulty in resolving relationships among sucker subfamilies (Chen \& Mayden,

437 2012; Doosey et al., 2010; Harris et al., 2002; Sun et al., 2007). Likewise, relationships among 438 the Myxocyprininae, Cycleptinae, and Ictiobinae lineages were incongruent across analyses of different datasets (Figs. 2, 3, S1-S4), but with two main patterns that we deemed subfamily pattern 1, with the form ((Myxocyprininae, Cycleptinae), Ictiobinae), and subfamily pattern 2, with Myxocyprininae sister to all other sucker subfamilies. We distinguished between these two

442 alternative hypotheses using a topological constraint test based on Bayes factors. The result 443 yielded log-marginal likelihood estimates and Bayes factors giving definitive weight of evidence against the unconstrained subfamily pattern 1 model. Given this result, a placement of Myxocyprininae as sister to all other suckers seems most probable at this point, thus we favor the patterns of subfamily relationships in our four-locus and Bayesian total-evidence dating

447 topologies that are consistent with this result. Nevertheless, the question still remains: What 448 factors have likely influenced the difficulty of our study and previous studies to resolve phylogenetic relationships among sucker subfamily lineages? Overall, our phylogenetic informativeness analyses highlight two potential explanations for the observed incongruence in subfamily relationships across analyses. First, PI profiling identified the mtDNA $1^{\text {st }}$ and $3^{\text {rd }}$

452 codon position data subsets as problematic character sets likely compromised by homoplasy due 453 to nucleotide saturation (Fig. 5); hence, we felt justified in excluding these sites from our final

454 divergence dating analyses. Second, our results suggest that predicted phylogenetic noise of the 455 combined datasets over the subfamily divergence epoch (Fig. S9) was most likely a limiting 456 factor for resolving Cycleptinae as sister to Ictiobinae. Whereas internode distances for

457 Catostominae and Myxocyprininae crown clades were generally longer, being $\sim 11$ Myr to 18 
458 Myr in length, and associated with significant posterior support, that for Cycleptinae + Ictiobinae

459 had a short internode distance of only 1 Myr (95\% HPDs: [0.01,9.1]) and non-significant

460 posterior support in our time tree (Fig. 4). Together with the more frequent incongruence and

461 lower support for Cycleptinae compared to Ictiobinae across our MrBayes topologies, this

462 suggests that Cycleptinae acted as a "rogue taxon" switching positions on the tree (Aberer et al.,

463 2013). We hypothesize that our BEAST total-evidence tree inferred subfamily relationships that

464 were more consistent with Bayes factor tests, and had greater nodal support for early-diverging

465 nodes, by limiting the rogue movements of Cycleptinae.

466 Monophyly of early-diverging sucker genera, and relationships within Ictiobus

467 The genera Myxocyprinus, Cycleptus, Carpiodes, and Ictiobus formed well-supported clades in

468 our results. However, relationships among Ictiobus species were resolved in a polytomy or

469 paraphyletic grade in several cases, limiting our resolution of this clade. These Ictiobus results

470 disagree with previous mtDNA- or nDNA-based studies resolving relationships among Ictiobus

471 species with strong maximum-likelihood bootstrap support (Doosey et al., 2010), and Smith's

472 (1992) hypothesis of relationships among four Ictiobus species based mainly on morphology.

473 Given these findings, and that our current results fail to unquestionably place the Cycleptinae as

474 sister to the Ictiobinae, drawing phylogenetic or taxonomic conclusions about Ictiobus species

475 relationships would seem premature, and we recommend more in-depth analyses of these taxa.

476

477

478

479

480

\section{Phylogenetic relationships among the Catostominae}

Within the Catostominae, our multilocus and total-evidence results strongly supported sister relationships between Thoburniini + Moxostomatini, and between Erimyzonini + Catostomini. These findings agree well with previous molecular results (Harris et al., 2002; Clements et al., 2012), except for mitochondrial trees in Doosey et al. (2010) showing the Erimyzonini as sister 
481 to all other clades within Catostominae. Interestingly, however, our catostomine relationships

482 conflict with the analysis of Smith (1992), whose morphological data we re-analyzed. In Smith's

483 (1992) sucker phylogeny, the Erimyzonini is resolved as sister to a clade containing what are

484 currently regarded as the Moxostomatini and Thoburniini (Harris \& Mayden, 2001; Harris et al.,

485 2002). Smith pointed out that this set of relationships was supported by $>20$ apomorphies that

486 changed at the node representing the MRCA of these lineages in his parsimony tree. But this

487 conclusion is only as sound as the phylogeny upon which character state transitions were mapped

488 by Smith (1992), which, at this node and several other key nodes, is rejected by our mtDNA,

489 nDNA, and multilocus trees, as well as total-evidence results from analyzing Smith's data

490 together with molecular datasets.

491 Regarding our Thoburniini + Moxostomatini clade, genus Thoburnia was inferred to be

492 paraphyletic based on the placement of T. atripinnis sister to the Hypentelium clade, mostly with

493 strong BPP support. Doosey et al. (2010) and Clements et al. (2012) obtained the same

494 relationship for T. atripinnis. However, our morphology tree resolved Thoburnia as

495 monophyletic, which is consistent with Smith's (1992) original analysis of the morphological

496 data we used, suggesting further data or analyses are needed to clarify these relationships. We

497 consistently inferred Hypentelium roanokense as sister to a clade of H. etowanum $+H$. nigricans,

498 across molecular, morphological, and total-evidence analyses, though with varying BPP (Figs. 3,

499 S1, S2, S4 and S5). These results match relationships inferred by Buth (1980) using isozyme data

500 reflecting variation at 40 putative loci. By contrast, our results conflict with Smith's (1992)

501 hypothesis, which resolved $H$. roanokense as sister to $H$. nigricans; however, this relationship

502 was based on a single morphological character, dermethmoid spine shape. Taking this into

503 consideration, the broad congruence between multiple data types, as well as our re-analysis of 
504 Smith's (1992) data, suggests high confidence in the inference that $H$. roanokense is the earliest

505 diverging lineage in the genus. Within our Moxostomatini clade, Moxostoma was monophyletic

506 consistent with previous analyses (e.g. Clements et al. 2012).

507 Relationships within the Erimyzonini and Catostomini were very similar to those in

508 Harris et al. (2002) and consistent with Doosey et al. (2010), but they contradicted Smith (1992),

509 especially by resolving relationships within Erimyzon while placing E. sucetta sister to E. tenuis.

510 As in previous molecular results for Erimyzonini, Erimyzon was monophyletic and sister to

511 Minytrema in our results. However, Catostomini genera were not generally obtained as

512 monophyletic, and in no case was Catostomus monophyletic relative to Chasmistes, Deltistes, or

513 Xyrauchen. Our molecular and total-evidence analyses consistently resolved 9 well-supported

514 major clades within Catostominae (e.g. Figs. 3, S1 and S2). Here, we focus on relationships

515 within Clade 5, which corresponded to the former subgenus Pantosteus, which Unmack et al.

516 (2014) recently elevated to genus. Smith (1966) recognized six species within Pantosteus: $P$.

517 clarkii, C. columbianus, $P$. discobolus, $P$. plebeius, $P$. platyrhynchus, and $P$. santaanae. We

518 sampled all of these, including both subspecies of $P$. discobolus, but consistently inferred a

519 polyphyletic Pantosteus, with P. nebuliferus (recognized as distinct from P. plebeius by Miller et

520 al., 2005; Nelson et al., 2004) falling within Clade 5 but C. columbianus placed in Clade 8

521 (discussed below). A clade with P. nebuliferus + P. plebeius was frequently sister to all

522 remaining Pantosteus (e.g. Fig. 3). Notwithstanding incongruent results among analyses in the

523 two papers, the consensus of results from our study and those of Unmack et al. (2014) seems to

524 lend strongest support to the former relationship, with $P$. santaanae sister to a clade containing

525 P. clarkii and P. discobolus lineages. The polyphyly of Pantosteus and nebuliferus-plebeius

526 sister relationship are concordant with the results of Doosey et al.'s (2010) analyses using RY- 
527 coding for third position mtDNA substitutions, although they inferred P. santaanae as sister to a

528 clade containing other members of Pantosteus. These results also agree with mitochondrial and

529 morphological analyses of Unmack et al. (2014). However, our results depart from Doosey et al.

530 (2010) and agree better with Unmack et al. (2014) in strongly supporting a sister relationship

531 between C. columbianus and C. tahoensis. That the morphological and molecular data analyzed

532 herein support the monophyly and diagnosability of Pantosteus relative to Catostomus, without

533 rendering Catostomus paraphyletic, strongly supports Unmack et al.'s (2014) decision to

534 redefine Pantosteus to exclude C. columbianus. We note that this taxonomic arrangement is also

535 consistent with studies on morphological and biochemical variation in western suckers (Koehn,

536 1969; Smith, 1992; Smith \& Koehn, 1971). Also, C. columbianus has an open frontoparietal

537 fontanelle, a key diagnostic character of this clade, whereas other Pantosteus species have the

538 frontoparietal fontanelle closed or reduced to a narrow slit (Smith, 1966).

539 "Catostomus" polyphyly and introgressive hybridization

540 As noted above, Catostomus was never resolved in our study as monophyletic relative to

541 Chasmistes, Deltistes, or Xyrauchen, and this result is concordant with phylogenetic results of

542 Doosey et al. (2010) based on mtDNA ND4/ND5 sequences. Hybridization of Catostomus with

543 Chasmistes, Deltistes, and Xyrauchen is well documented (Buth et al., 1987; Markle et al., 2005;

544 Mock et al., 2006; Tranah \& May, 2006), and may be related to the non-monophyly of

545 Catostomus relative to Chasmistes and Deltistes. However, while Xyrauchen texanus has been

546 documented to hybridize with C. latipinnis and C. insignis (Buth et al., 1987; Hubbs \& Miller,

547 1953), the majority of these reports evaluate hybridization between $X$. texanus and C. latipinnis

548 (Buth et al., 1987). Samples of Xyrauchen used in this study originated from the Dexter National

549 Fish Hatchery, which obtained the original hatchery stock of Razorback sucker from Lake 
550 Mohave, Arizona, where hybridization with C. latipinnis has been documented but allozyme

551 evidence indicates only low levels of introgression of $C$. latipinnis with $X$. texanus (Buth et al.,

552 1987). Therefore, placement of $C$. insignis sister to $X$. texanus here and by Doosey et al. (2010)

553 suggests that introgression is not a factor in either study. As such, "Xyrauchen" embedded within

554 Catostomus renders the latter polyphyletic. Even if hybridization-mediated introgression were

555 considered as an ad hoc explanation of this pattern, this is difficult to distinguish from the more

556 parsimonious hypothesis of common ancestry, and the available data do not demonstrate that any

557 hybridization events among these taxa have corresponded to the Neogene-present timeframe of

558 their divergences inferred by our time tree. Thus, we advocate the tentative placement of

559 "Xyrauchen" into synonymy with Catostomus until additional fossil or molecular evidence

560 rejects an inference of common ancestry in favor of Neogene hybridization of these taxa.

561 Bayesian total-evidence dating and relaxed-clock partitioning

562 In showing that the best clock-partitioned BEAST models excluded sites identified as

563 problematic in our PI profiling analysis, the results of our Bayes factor clock-partitioning model

564 comparisons bolster Ho and Lanfear's (2010) recommendation that accounting for differences in

565 substitution rates among data partitions through clock-partitioning is not only feasible but also

566 improves phylogenetic divergence dating models. We believe that by employing a clock-

567 partitioning scheme objectively chosen in this way allowed our final BEAST FBD analysis to

568 more correctly estimate topology and rate variance among branches, and better handle rate

569 heterogeneity of the retained characters. However, while the inclusion of fossil taxa in an FBD

570 model in the final BEAST analysis certainly improved our divergence time estimates over what

571 might be obtained using node calibration or tip-dating methods (e.g. Arcila et al., 2015;

572 Gavryushkina et al., 2017), one limitation of this analysis was that nodal support was reduced 
573 within the Catostomini and Ictiobinae. This pattern was caused by rogue placements of fossil

574 taxa lacking character data, which were constrained within these crown groups but made up

$575 \geq 50 \%$ of tip sampling (Fig. 4). Still, this mainly caused misleading relationships and lowered

576 nodal support within the Catostomini; after removing fossil taxa, relationships within Ictiobinae

577 would be essentially identical to our preferred MrBayes topologies. After pruning extinct taxa,

578 our time tree will provide a suitable basis for interrogating the comparative biogeography and

579 evolution of all groups of suckers, except for patterns within Catostomini. One alternate way

580 forward for researchers interested in using our results for comparative phylogenetics would be to

581 convert one of our preferred topologies (Figs. 3 and S2) to an ultrametric tree while constraining

582 subfamily and tribal node ages to mean $t_{\mathrm{MRCA}}$ estimates shown in Fig. 4.

583 A major goal of our study was to use our final total-evidence dating results to test

584 hypotheses on the temporal diversification of suckers. Our divergence dating results (Fig. 4)

585 generally agree with the fossil record but reject or confirm different molecular hypotheses about

586 the temporal diversification of sucker subfamilies. Unsurprisingly, given our incorporation of all

587 fossil sucker lineages in the paleontological literature under an FBD model (accounting for

588 extant and fossil sampling levels), our BEAST results strongly support hypothesis $H_{4}$ that

589 Catostomidae lineages have diversified since $\sim 50 \mathrm{Ma}$ in the Early Eocene, which is widely

590 accepted as the minimum age of the origin of suckers based on stratigraphic information for the

591 oldest sucker fossils (review and refs. in Appendix S1). Our results also support Sun et al.'s

592 (2007) proposal, or our hypothesis $H_{3}$, that catostomine lineages in the most speciose sucker

593 subfamily went on to diversify since $\sim 20 \mathrm{Ma}$. Indeed, initial divergences and subsequent

594 diversification of all four catostomine tribes has proceeded since around $\sim 34-17.6 \mathrm{Ma}$ in the

595 Eocene-Miocene, with $95 \%$ credible intervals ranging from 43 to $11.04 \mathrm{Ma}$ (Fig. 4), and the 
$596 t_{\mathrm{MRCA}} \mathrm{S}$ for $\sim 81 \%(64 / 79)$ of extant species/lineages in our time tree (all catostomines) coincide

597 with the last 20 million years.

598 In contrast to hypotheses $H_{3}$ and $H_{4}$ discussed above, we reject two previous molecular

599 hypotheses about the tempo of sucker evolution advanced by Sun et al. (2007). First, we reject

600 hypothesis $H_{1}$ because we infer that the Asian Myxocyprininae diverged from North American

601 suckers during the Late Cretaceous, and the 95\% credible intervals for this divergence do not

602 overlap with their proposed 14 Ma Miocene date for the MRCA of Myxocyprinus and

603 Cycleptus. Second, we reject $\mathrm{H}_{2}$ given that we infer an early Eocene origin for Ictiobinae,

604 including the extinct $\uparrow$ Amyzon and $\uparrow$ Vasnetzovia ictiobine lineages, and this vastly predates Sun

605 et al.'s (2007) proposed origin of the clade. Given Sun et al. (2007) produced divergence time

606 estimates using only cyt $b$ divergences and a global molecular clock assuming a 2.0\% $\mathrm{Myr}^{-1}$

607 pairwise rate for vertebrate mtDNA, there are too many methodological distinctions between our

608 approach and theirs to pinpoint a single factor causing our results to contrast theirs so strongly.

609 However, our more comprehensive and nuanced approach using Bayesian total-evidence dating

610 not only allowed us to use a realistic FBD tree prior incorporating the speciation-extinction-

611 fossilization sampling process (Gavryushkina et al., 2017), but also permitted estimation of

612 evolutionary rates for each character subset analyzed. We inferred a slower rate of evolution for

613 mtDNA $2^{\text {nd }}$ position sites, $6.53 \times 10^{-4}$ substitutions site ${ }^{-1} \mathrm{Myr}^{-1}$, and in fact all DNA subsets

614 (mean: 0.0055 substitutions site $^{-1} \mathrm{Myr}^{-1}$ ), than the global rate applied by Sun et al. (2007). This

615 is partly due to our best model excluding the most variable mtDNA codon sites, but it appears

616 that differences between our $t_{\mathrm{MRCA}}$ estimates and theirs are not fully accounted for based on

617 substitution rates alone. Nevertheless, our more appropriate modeling of the evolutionary

618 processes producing variation in sucker DNA sequences and morphological characters, and 
619 extant and fossil taxon sampling, has allowed us to estimate older and undoubtedly more

620 accurate divergence dates, especially for deeper nodes in the sucker phylogeny.

621 We infer divergence times for major sucker lineages that are conspicuously older than

622 those recently estimated from multilocus analyses of other North American freshwater fish

623 clades, including sunfishes and black basses (Centrarchidae; Near et al., 2005, 2011), bullhead

624 and madtom catfishes (Ictaluridae; Hardman \& Hardman, 2008), and darters (Etheostomatinae;

625 Near et al., 2011). Whereas the diversification of these major lineages has occurred since around

626 the Eocene-Oligocene transition $\sim 34 \mathrm{Ma}$, a time of global cooling (Zachos et al., 2001), we infer

627 an earlier Late Cretaceous-Eocene age for the onset of sucker subfamily divergences. While tip-

628 dating approaches can lead to older divergence dates (e.g. O'Reilly et al. 2015), we believe that

629 this result accurately reflects the relatively longer timeframe of sucker evolution captured by the

630 fossil record. This general timeframe for sucker evolution also correlates well to the Late

631 Paleocene Thermal Maximum, a period of greater ambient and sea-surface temperatures, higher

632 sea levels, and higher precipitation and humidity (Zachos et al., 2001). Sucker diversification

633 thus appears to have initiated during a period of climate change and sea level rise, which may

634 have facilitated the isolation of ancestral sucker populations. Our results also suggest that

635 approximately 4 to 7 sucker genera may have been present in North America by the Oligocene, a

636 period coinciding with the arrival of minnows in the family Cyprinidae on the continent based on

637 the broader fossil record of North American teleost fishes (e.g. Cavender 1986). Together with

638 the molecular results from other studies above, this implies that the subsequent diversification of

639 these genera, including at least Cycleptus, $\uparrow$ Amyzon, Ictiobus, and Carpiodes as well as the

640 speciose Catostominae, would have coincided with the diversification of most other major

641 lineages of North American freshwater fishes. 


\section{Conclusions}

643 We have presented the results of a phylogenetic analysis of Holarctic sucker fishes (family

644 Catostomidae) drawing on the most comprehensive dataset to date and inferring, separately and

645 jointly, the phylogeny and divergence times of suckers while including fossil taxa as tips. Our

646 molecular and total-evidence results corroborated relationships hypothesized in previous

647 molecular studies and yielded evidence in favor of some new hypotheses of relationships within

648 and among subfamilies, for example with Bayes factor support for Myxocyprininae sister to all

649 other sucker lineages. Our study also highlights how using PI profiling to identify problematic

650 character sets can subsequently improve or provide additional evidence for clock-partitioning

651 scheme choice during Bayesian relaxed-clock divergence dating. Our divergence-dating results

652 strongly supported the hypotheses that Catostomidae lineages have diversified since $\sim 50 \mathrm{Ma}$ in

653 the Early Eocene (Uyeno \& Smith, 1972), and that tribes within the most speciose subfamily,

654 Catostominae, have diversified since 20 Ma in the Eocene-Miocene (Smith, 1992; Sun et al.,

655 2007). Moreover, we hypothesized that incongruent subfamily relationships were driven in part

656 by problematic mtDNA $1^{\text {st }}$ and $3^{\text {rd }}$ codon sites, and by "rogue taxon" movements of Cycleptinae

657 and fossil taxa, for example in our FBD process time tree. Our analysis could be extended to test

658 this latter hypothesis using additional statistical analyses of rogue taxa (e.g. Aberer et al., 2014)

659 and internode uncertainty (Zhou et al., 2017), and by additional resolution analyses employing

660 Monte Carlo simulations and tests of their assumptions (Townsend et al., 2012), which were

661 beyond the scope of the present study. Nevertheless, our results suggest that future studies of

662 suckers will benefit from using PI profiles as a predictive tool to select loci for subsequent

663 phylogenetic analyses (Dornburg et al., 2014).

\section{Acknowledgements}


665 We are grateful to the following colleagues for providing specimens used in this study: Tom

666 Turner and Alexandra Snyder, Museum of Southwest Biology; Karen Mock and Brian Cardall,

667 Utah State University; Mike Bessert, University of Nebraska Lincoln; Douglas Markle, Oregon

668 State University; Dennis Shiozawa, Monte L. Bean Life Science Museum, Brigham Young

669 University; Vicky Albert and Louis Bernatchez, Université Laval; Andrew Simons, Bell

670 Museum of Natural History, University of Minnesota; and Morgan Raley, North Carolina State

671 Museum of Natural Sciences. We thank Kenneth De Baets, Stephan Koblmüller, Guillermo Ortí,

672 Rodolfo Pérez-Rodríguez, and three anonymous reviewers for valuable comments on earlier

673 versions of this manuscript, and we thank Andrew Eckert for useful discussions of analyses and

674 presentation. We also thank the Brigham Young University Fulton Supercomputing Lab for

675 providing generous computational resources.

\section{References}

677 Aberer AJ, Krompass D, Stamatakis A. 2013. Pruning rogue taxa improves phylogenetic accuracy: an

678 efficient algorithm and webservice. Systematic Biology 62:162-166.

679 Agassiz L. 1854. Notice of a collection of fishes from the southern bend of the Tennessee River, in the 680 State of Alabama. American Journal of Science and Arts 28 second series 17:297-308,353-365.

681 Arcila D, Pyron RA, Tyler JC, Ortí G, Betancur-RR. 2015. An evaluation of fossil tip-dating versus node682 age calibrations in tetraodontiform fishes (Teleostei: Percomorphaceae). Molecular Phylogenetics 683 and Evolution 82:131-145.

684 Baele G, Lemey P, Bedford T, Rambaut A, Suchard MA, Alekseyenko AV. 2012. Improving the 685 accuracy of demographic and molecular clock model comparison while accommodating 686 phylogenetic uncertainty. Molecular Biology and Evolution 29:2157-2167.

687 Bagley JC. 2017. justincbagley/PIrANHA: PIrANHA version 0.1.4 [Data Set]. Zenodo. Available at 688 http://doi.org/10.5281/zenodo.571185.

689 Bouckaert R, Heled J, Künert D, Vaughan TG, Wu CH, Xie D, Suchard MA, Rambaut A, Drummond AJ. 690 2014. BEAST2: a software platform for Bayesian evolutionary analysis. PLoS Computational Biology 10:e1003537. 
692 Brandley MC, Wang Y, Guo X, Montes de Oca AN, Fería-Ortíz M, Hikida T, Ota H. 2011.

693

694

695

696

697

698

699

700

701

702

703

704

705

706

707

708

709

710

711

712

713

714

715

716

717

718

719

720

721

722

723

724

725

Accommodating heterogeneous rates of evolution in molecular divergence dating methods: an example using intercontinental dispersal of Plestiodon (Eumeces) lizards. Systematic Biology 60:3-15.

Bruner JC. 1991. Comments on the genus Amyzon (family Catostomidae). Journal of Paleontology 65:678-686.

Buth DG. 1980. Genetics and systematic relationships in the catostomid genus Hypentelium. Copeia 1980:280-290.

Buth DG, Murphy RW, Ulmer L. 1987. Population differentiation and introgresseve hybridization of the flannelmouth sucker and of hatchery and native stocks of the razorback sucker. Transactions of the American Fisheries Society 116:103-110.

Cavender T. 1986. Review of the fossil history of North American freshwater fishes. In: Hocutt CH, Wiley EO, eds. The Zoogeography of North American Freshwater Fishes. New York: John Wiley and Sons. 699-724

Chang M, Miao D, Chen Y, Zhou J, Pingfu C. 2001. Suckers (Fish, Catostomidae) from the Eocene of China account for the family's current disjunct distributions. Science in China Series D-Earth Sciences 44:577-586.

Chen W-J, Mayden RL. 2012. Phylogeny of suckers (Teleostei: Cypriniformes: Catostomidae): further evidence of relationships provided by the single-copy nuclear gene IRBP2. Zootaxa 3586:195210.

Chen W-J, Miya M, Saitoh K, Mayden RL. 2008. Phylogenetic utility of two existing and four novel nuclear gene loci in reconstructing Tree of Life of ray-finned fishes: the order Cypriniformes (Ostariophysi) as a case study. Gene 423:125-134.

Chow S, Takeyama H. 1998. Intron length variation observed in the creatine kinase and ribosomal protein genes of the swordfish Xiphias gladius. Fisheries Science 64:397-402.

Clarke JA, Middleton K. 2008. Mosaicism, modules, and the evolution of birds: results from a Bayesian approach to the study of morphological evolution using discrete character data. Systematic Biology 57:185-201.

Clements MD, Bart Jr. HL, Hurley DL. 2012. A different perspective on the phylogenetic relationships of the Moxostomatini (Cypriniformes: Catostomidae) based on cytochrome- $b$ and Growth Hormone intron sequences. Molecular Phylogenetics and Evolution 63: 159-167.

Doosey M, Bart H, Saitoh K, Miya M. 2010. Phylogenetic relationships of catostomid fishes (Actinopterygii: Cypriniformes) based on mitochondrial ND4/ND5 gene sequences. Molecular Phylogenetics and Evolution 54:1028-1034. 
726 Dornburg A, Townsend JP, Friedman M, Near TJ. 2014. Phylogenetic informativeness reconciles ray-

727

728

729

730

731

732

733

734

735

736

737

738

739

740

741

742

743

744

745

746

747

748

749

750

751

752

753

754

755

756

757

758

759

finned fish molecular divergence times. BMC Evolutionary Biology 14:169.

Drummond AJ, Suchard MA, Xie D, Rambaut A. 2012. Bayesian phylogenetics with BEAUti and the BEAST 1.7. Molecular Biology and Evolution 29:1969-1973.

Ferris SD, Whitt GS. 1978. Phylogeny of tetraploid catostomid fishes based on the loss of duplicate gene expression. Systematic Zoology 27:189-206.

Gavryushkina A, Heath TA, Ksepka DT, Stadler T, Welch D, Drummond AJ. 2017. Bayesian totalevidence dating reveals the recent crown radiation of penguins. Systematic Biology 66:57-73.

Gavryushkina A, Welch D, Stadler T, Drummond AJ. 2014. Bayesian inference of sampled ancestor trees for epidemiology and fossil calibration. PLoS Computational Biology 10(12):e1003919.

Hardman M, Hardman LM. 2008. The relative importance of body size and paleoclimatic change as explanatory variables influencing lineage diversification rate: an evolutionary analysis of bullhead catfishes (Siluriformes: Ictaluridae). Systematic Biology 57:116-130.

Harris PM, Hubbard G, Sandel M. 2014. Catostomidae: Suckers. In: Warren ML, Burr BM, eds. Freshwater fishes of North America: Volume 1: Petromyzontidae to Catostomidae. Baltimore, MD: Johns Hopkins University Press. 451-502

Harris PM, Mayden RL. 2001. Phylogenetic relationships of major clades of Catostomidae (Teleostei: Cypriniformes) as inferred from mitochondrial SSU and LSU rDNA sequences. Molecular Phylogenetics and Evolution 20:225-237.

Harris PM, Mayden RL, Perez HE, Garcia de Leon F. 2002. Phylogenetic relationships of Redhorse (Moxostoma) and Jumprock (Scartomyzon) suckers (Cypriniformes: Catostomidae) based on mitochondrial cytochrome $b$ sequence data. Journal of Fish Biology 61:1433-1452.

Heath TA, Hedtke SM, Hillis DM. 2008. Taxon sampling and the accuracy of phylogenetic analyses. Journal of Systematics and Evolution 46:239-257.

Heath TA, Huelsenbeck JP, Stadler T. 2014. The fossilized birth-death process for coherent calibration of divergence-time estimates. Proceedings of the National Academy of Sciences of the United States of America 111:E2957-E2966.

Ho SY, Lanfear R. 2010. Improved characterisation of among-lineage rate variation in cetacean mitogenomes using codon-partitioned relaxed clocks. Mitochondrial DNA 21:138-146.

Hubbs CL. 1930. Materials for a revision of the catostomid fishes of eastern North America. Miscellaneous Publications of the Museum of Zoology of the University of Michigan, No. 20.

Hubbs CL, Miller RR. 1953. Hybridization in nature between the fish genera Catostomus and Xyrauchen. Papers of the Michigan Academy of Science, Arts and Letters 38:207-234.

Jenkins RE. 1970. Systematic studies of the catostomid fish tribe Moxostomatini. Ithaca, NY: Cornell 
760

761

762

763

764

765

766

767

768

769

770

771

772

773

774

775

776

777

778

779

780

781

782

783

784

785

786

787

788

789

790

791

792

793

University.

Kass RE, Raftery AE. 1995. Bayes factors. Journal of the American Statistical Association 90:773-795.

Katoh K, Toh H. 2008. Recent developments in the MAFFT multiple sequence alignment program. Bioinformatics 9:286-298.

Kearse M, Moir R, Wilson A, Stones-Havas S, Cheung M, Sturrock S, Buxton S, Cooper A, Markowitz S, Duran C, Thierer T, Ashton B, Mentjies P, Drummond A. 2012. Geneious Basic: an integrated and extendable desktop software platform for the organization and analysis of sequence data. Bioinformatics 28:1647-1649.

Kettratad J, Markle DF. 2010. Redescription of the Tyee Sucker, Catostomus tsiltcoosensis (Catostomidae). Western North American Naturalist 70:273-287.

Koehn RK. 1969. Hemoglobins of fishes of the genus Catostomus from western North America. Copeia 1969:21-30.

Lanfear R, Calcott B, Ho SYW, Guindon S. 2012. PartitionFinder: combined selection of partitioning schemes and substitution models for phylogenetic analyses. Molecular Biology and Evolution 29: 1695-1701.

Lewis PO. 2001. A likelihood approach to estimating phylogeny from discrete morphological character data. Systematic Biology 50:913-925.

López-Giráldez F, Townsend JP. 2011. PhyDesign: an online application for profiling phylogenetic informativeness. BMC Evolutionary Biology 11:152.

Markle DF, Cavalluzzi MR, Simon DC. 2005. Morphology and taxonomy of Klamath Basin suckers (Catostomidae). Western North American Naturalist 65:473-489.

Mayden RL, Chen WJ, Bart Jr. HL, Doosey MH, Simons AM, Tang KL, Wood RM, Agnew MK, Yang L, Hirt MV, Clements MD, Saitoh K, Sado T, Miya M, Nishida M. 2009. Reconstructing the phylogenetic relationships of the earth's most diverse clade of freshwater fishes - order Cypriniformes (Actinopterygii: Ostariophysi): a case study using multiple nuclear loci and the mitochondrial genome. Molecular Phylogenetics and Evolution 51:500-514.

Mayden RL, Tang KL, Wood RM, Chen W.J, Agnew MK, Conway KW, Yang L, Simons AM, Bart HL, Harris PM, Li J, Wang X, Saitoh K, He S, Liu H, Chen Y, Mutsumi N, Miya M. 2008. Inferring the Tree of Life of the order Cypriniformes, the earth's most diverse clade of freshwater fishes. Journal of Systematics and Evolution 46:424-438.

Miller RR. 1959. Origin and affinities of the freshwater fish fauna of western North America. In: Hubbs CL, ed. Zoogeography. Washington, D.C.: American Association for the Advancement of Science Publication 51. 187-222

Miller RR, Minckley WL, Norris SM. 2005. Freshwater fishes of Mexico. Chicago, IL: University of 
794

795

796

797

798

799

800

801

802

803

804

805

806

807

808

809

810

811

812

813

814

815

816

817

818

819

820

821

822

823

824

825

826

827

Chicago Press.

Mock KE, Evans RP, Crawford M, Cardall BL, Janecke SU, Miller MP. 2006. Rangewide molecular structuring in the Utah sucker (Catostomus ardens). Molecular Ecology 15:2223-2238.

NatureServe, 2013. Moxostoma lacerum. The IUCN Red List of Threatened Species. Version 2015.2. $<$ www.iucnredlist.org $>$. Last accessed on 01 August 2015.

NatureServe, 2014. Chasmistes cujus. Red List of Threatened Species. Version 2015.2.

$<$ www.iucnredlist.org $>$. Last accessed on 01 August 2015.

Near TJ, Bolnick DI, Wainwright PC. 2005. Fossil calibrations and molecular divergence time estimates in centrarchid fishes (Teleostei: Centrarchidae). Evolution 59:1768-1782.

Near TJ, Bossu CM, Bradburd GS, Carlson RL, Harrington RC, Hollingsworth Jr. PR, Keck BP, Etnier DA. 2011. Phylogeny and temporal diversification of darters (Percidae: Etheostomatinae). Systematic Biology 60:565-595.

Near TJ, Eytan RI, Dornburg A, Kuhn KL, Moore JA, Davis MP, Wainwright PC, Friedman M, Smith WL. 2012. Resolution of ray-finned fish phylogeny and timing of diversification. Proceedings of the National Academy of Sciences of the United States of America 109:13698-13703.

Nelson JS, Crossman EJ, Espinosa-Perez H, Findley LT, Gilbert CR, Lea RN, Williams JD. 2004. Common and Scientific Names of Fishes from the United States, Canada, and Mexico. Bethesda, MD: American Fisheries Society Special Publication 29.

O’Reilly JE, dos Reis M, Donoghue PC. 2015. Dating tips for divergence-time estimation. Trends in Genetics, 31:637-650.

Pagel M, Meade A. 2014. BayesTraits (1st edition). Reading, UK. Available at http://www.evolution.rdg.ac.uk/BayesTraits.html.

Pond SLK, Frost SDW, Muse SV. 2005. HyPhy: hypothesis testing using phylogenies. Bioinformatics 21:676-679.

Pyron RA. 2011. Divergence time estimation using fossils as terminal taxa and the origins of Lissamphibia. Systematic Biology 60:466-481.

Rambaut A, Drummond AJ. 2014. Tracer v1.5. Available at http://beast.bio.edu.ac.uk/Tracer.

Robins CR, Raney EC. 1956. Studies of the catostomid fishes of the genus Moxostoma, with descriptions of two new species. Cornell University Agricultural Experiment Station Memoir 343, 1-56.

Ronquist F, Teslenko M, van der Mark P, Ayres DL, Darling A, Höhna S, Larget B, Liu L, Suchard MA, Huelsenbeck JP. 2012. MrBayes 3.2: efficient Bayesian phylogenetic inference and model choice across a large model space. Systematic Biology 61:539-542.

Sagahi-Maroof MA, Soliman KM, Jorgensen RA, Allard RW. 1984. Ribosomal DNA spacer-length polymorphism in barley: Mendelian inheritance, chromosomal location, and population 
828

829

830

831

832

833

834

835

836

837

838

839

840

841

842

843

844

845

846

847

848

849

850

851

852

853

854

855

856

857

858

859

860

861

dynamics. Proceedings of the National Academy of Sciences of the United States of America 81:8014-8019.

Saitoh K, Sado T, Mayden RL, Hanzawa N, Nakamura K, Nishida M, Miya M. 2006. Mitogenomic evolution and interrelationships of the Cypriniformes (Actinopterygii: Ostariophysi): the first evidence toward resolution of higher-level relationships of the world's largest freshwater fish clade based on 59 whole mitogenome sequences. Journal of Molecular Evolution 63:826-841.

Smith GR. 1966. Distribution and evolution of the North American catostomid fishes of the subgenus Pantosteus, genus Catostomus. Miscellaneous Publications of the Museum of Zoology of the University of Michigan 129:1-132.

Smith GR. 1992. Phylogeny and biogeography of the Catostomidae, freshwater fishes of North America and Asia. In: Mayden RL, ed. Systematics, historical ecology, and North American freshwater fishes. Stanford, CA: Stanford University Press. 778-813

Smith GR, Dowling TE, Gobalet KW, Lugaski T, Shiozawa DK, Evans RP. 2002. Biogeography and timing of evolutionary events among Great Basin fishes. In: Hershler R, Madsen DB, Currey DR, eds. Great Basin aquatic systems history. Washington, D.C.: Smithsonian Institution Press. 175234

Smith GR, Koehn RK. 1971. Phenetic and cladistic studies of biochemical and morphological characteristics of Catostomus. Systematic Zoology 20:282-297.

Sun YH, Xie CX, Wang WM, Liu SY, Treer T, Chang MM. 2007. The genetic variation and biogeography of catostomid fishes based on mitochondrial and nucleic DNA sequences. Journal of Fish Biology 70:291-309.

Tranah GJ, May B. 2006. Patterns of intra- and interspecies genetic diversity in Klamath River Basin suckers. Transactions of the American Fisheries Society 135:306-316.

Townsend JP. 2007. Profiling phylogenetic informativeness. Systematic Biology 56:222-231.

Townsend JP, Leuenberger C. 2011. Point of View: Taxon sampling and the optimal rates of evolution for phylogenetic inference. Systematic Biology 60:358-365.

Townsend JP, López-Giráldez F, Friedman R. 2008. The phylogenetic informativeness of nucleotide and amino acid sequences for reconstructing the vertebrate tree. Journal of Molecular Evolution 67:437-447.

Townsend JP, Su Z, Tekle Y. 2012. Phylogenetic signal and noise, predicting the power of a dataset to resolve phylogeny. Systematic Biology 5:835-849.

Unmack PJ, Dowling TE, Laitinen NJ, Secor CL, Mayden RL, Shiozawa DK, Smith GR. 2014. Influence of introgression and geological processes on phylogenetic relationships of western North American mountain suckers (Pantosteus, Catostomidae). PLoS One 9:e90061. 
862 Uyeno T, Smith GR. 1972. Tetraploid origin of the karyotype of catostomid fishes. Science 175:644-646.

863 Warren Jr. ML, Burr BM, Walsh SJ, Bart HL, Cashner RC, Etnier DA, Freeman BJ, Kuhajda BR,

864 Mayden RL, Robison HW, Ross ST. 2000. Diversity, distribution, and conservation status of the 865 native freshwater fishes of the southern United States. Fisheries 25:7-31.

866 Xie W, Lewis PO, Fan Y, Kuo L, Chen MH. 2011. Improving marginal likelihood estimation for

867 Bayesian phylogenetic model selection. Systematic Biology 60:150-160.

868 Zhou X, Lutteropp S, Czech L, Stamatakis A, von Looz M, Rokas A. 2017. Quartet-based computations

869 of internode certainty provide accurate and robust measures of phylogenetic incongruence.

$870 \quad$ bioRxiv 168526. 


\section{Table $\mathbf{1}$ (on next page)}

Summary of post-systematic phylogenetic and taxonomic studies of suckers in the family Catostomidae

Abbreviations: ML, maximum likelihood; MP, maximum parsimony; $n$, sample size, including ingroup and outgroup taxa or lineages; UPGMA, unweighted pair-group method with arithmetic mean; Wagner, Wagner method for inferring 'most parsimonious' tree. 


\begin{tabular}{|c|c|c|c|c|}
\hline Study & $n$ & Data type & Analysis & Supported clades/relationships \\
\hline Ferris \& Whitt (1978) & 30 & $\begin{array}{l}20 \text { isozyme loci (loss of } \\
\text { duplicate gene expression) }\end{array}$ & Wagner & $\begin{array}{l}\text { Ictiobinae }+(\text { Cycleptinae }+ \text { Catostominae }) \text {, three } \\
\text { catostomin tribes }\end{array}$ \\
\hline Smith (1992) & 64 & $\begin{array}{l}157 \text { morphological, } \\
\text { biochemical and early life- } \\
\text { history transformation series }\end{array}$ & MP & $\begin{array}{l}\text { Ictiobinae }+ \text { (Cycleptinae + Catostominae), } \\
\text { Moxostoma in paraphyletic grade with } \\
\text { "Scartomyzon" within Moxostomatini; also } \\
\text { trichotomy of M. ariommum + Thoburnia }+ \\
\text { Hypentelium }\end{array}$ \\
\hline $\begin{array}{l}\text { Harris \& Mayden } \\
(2001)\end{array}$ & 16 & $\begin{array}{l}\text { mtDNA SSU and LSU rDNA } \\
\text { sequences }\end{array}$ & MP & $\begin{array}{l}\text { four monophyletic subfamilies, Thoburniini } \\
\text { resurrected and includes Hypentelium; } \\
\text { Catostomini + Erimyzonini and Moxostomatini + } \\
\text { Thoburniini }\end{array}$ \\
\hline $\begin{array}{l}\text { Harris \& Mayden } \\
(2002)\end{array}$ & 50 & $\begin{array}{l}\text { mtDNA cytochrome } b \text { (cyt } b) \\
\text { gene }\end{array}$ & MP and ML & $\begin{array}{l}\text { four monophyletic subfamilies, provisional } \\
\text { Thoburniini; "Scartomyzon" as a junior synonym } \\
\text { of Moxostoma }\end{array}$ \\
\hline Sun et al. (2007) & 17 & mtDNA cyt $b$ gene & UPGMA & $\begin{array}{l}\text { monophyletic Ictiobinae and Catostominae; } \\
\text { Moxostomatini + Catostomini }\end{array}$ \\
\hline Doosey et al. (2010) & 60 & $\begin{array}{l}\text { mtDNA NADH subunit } 4 \text { and } \\
5(\mathrm{ND} 4 / 5) \text { sequences }\end{array}$ & ML & $\begin{array}{l}\text { ((Cycleptinae, (Myxocyprininae, Ictiobinae)), } \\
\text { Catostominae); also among catostomins: } \\
\text { Erimyzonini + (Moxostomatini + Thoburniini) }\end{array}$ \\
\hline $\begin{array}{l}\text { Chen \& Mayden } \\
(2012)\end{array}$ & 67 & $\begin{array}{l}\text { interphotoreceptor retinoid- } \\
\text { binding protein (IRBP) } \\
\text { sequences }\end{array}$ & ML & $\begin{array}{l}\text { supported previous relationships including } \\
\text { monophyly of subfamilies and tribes except } \\
\text { Thoburniini }\end{array}$ \\
\hline Clements et al. (2012) & 45 & growth hormone intron $(\mathrm{GHI})$ & ML & para-/polyphyletic Moxostoma and Scartomyzon \\
\hline Unmack et al. (2014) & 24 & $\begin{array}{l}\text { morphology, plus cyt } b \text { and } \\
\text { other mtDNA gene sequences }\end{array}$ & $\begin{array}{l}\text { MP, ML, and } \\
\text { Bayesian }\end{array}$ & $\begin{array}{l}\text { monophyletic Pantosteus within Catostomini, } \\
\text { except for Catostomus }(P .) \text { columbianus } \\
\text { (potential hybrid origin) }\end{array}$ \\
\hline
\end{tabular}




\section{Table 2 (on next page)}

List of sequences used in the present study including museum/field numbers and GenBank accession numbers.

Sequences generated during this study are shown in bold. Dash symbol, ' - ', indicates no sequence was available.

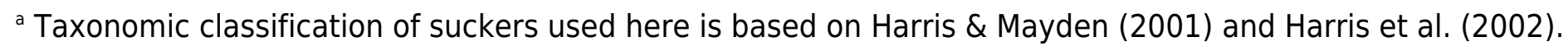

${ }^{\mathrm{b}}$ Institutional, project, and individual abbreviations: BRK, Bernard R. Kuhajda; CToL, Cypriniformes Tree of Life Project; DAN, David A. Neely; JEB, James E. Brooks; JFBM, (James Ford) Bell Museum of Natural History, University of Minnesota; HLB, Henry L. Bart, Jr.; MSB, Museum of Southwest Biology; PBB, Peter B. Berendzen; UAIC, University of Alabama Ichthyological Collection; USU, Utah State University; UNL, University of Nebraska Lincoln; OS, Oregon State University; BYU, Monte L. Bean Life Science Museum, Brigham Young University; Louis Bernatchez, Université Laval; NCSM, North Carolina State Museum of Natural Sciences; and TU, Tulane University Biodiversity Research Institute (formerly Tulane University Museum of Natural History). 


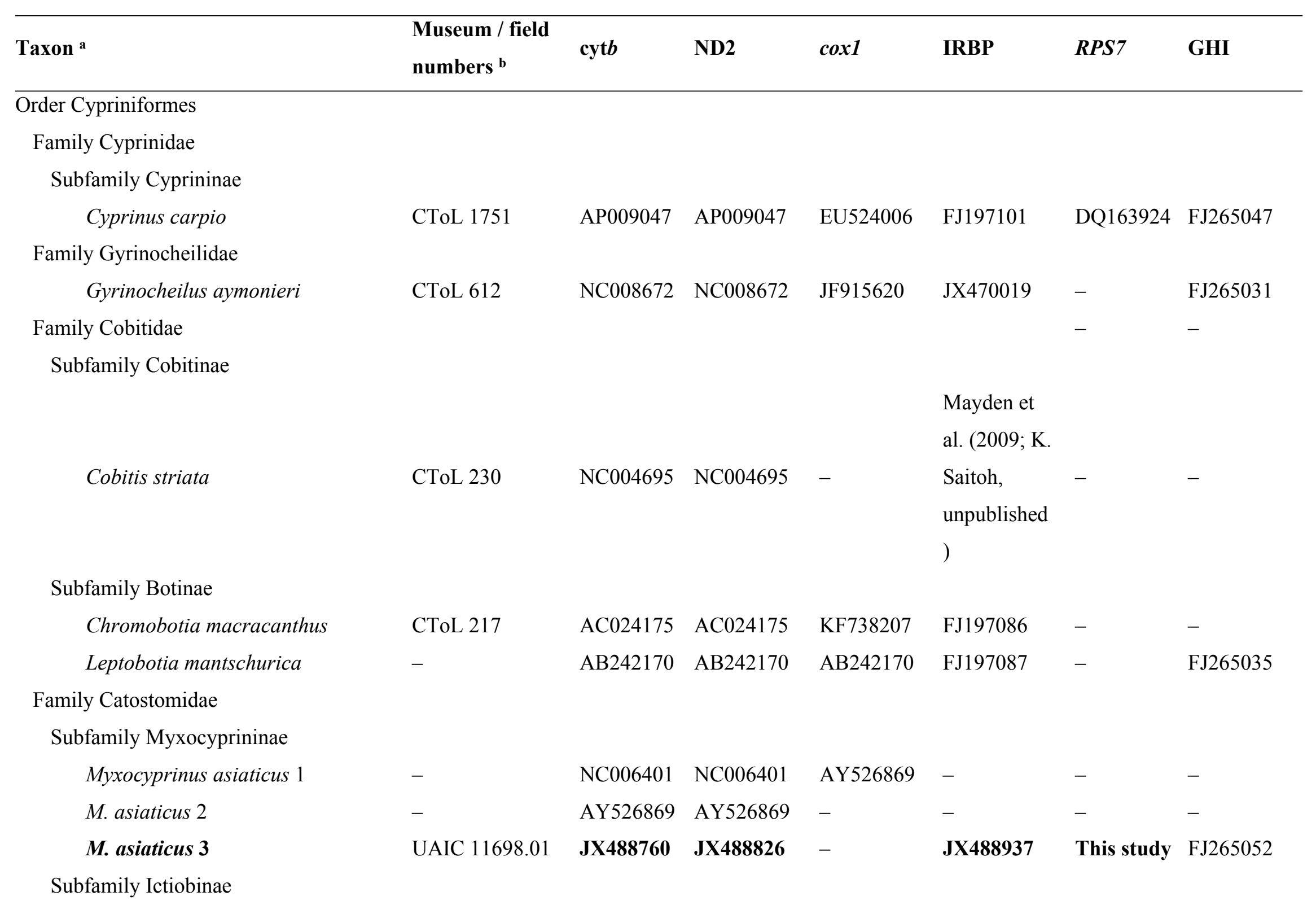


Carpiodes carpio 1

Car. carpio 2

Car. cyprinus

Car. velifer

Ictiobus bubalus 1

I. bubalus 2

I. bubalus 3

I. cyprinellus 1

I. cyprinellus 2

I. niger 1

I. niger 2

Subfamily Cycleptinae

Cycleptus elongatus 1

Cyc. elongatus 2

Cyc. meridionalis

Subfamily Catostominae

Tribe Catostomini

Catostomus ardens 1

C. ardens 2

C. bernardini Río Papogochic

C. bernardini Río Batopilas 1

C. bernardini Río Batopilas 2

C. bernardini Río Yecora

C. cahita 1

-
UAIC 11219.08
TU 157.01
TU 108.16
TU 124.07
TU 120.01
TU 244.03
TU 101.05
TU 107.15
TU 121.01
TU 124.06

AY366087

AF454867

JX488761

JX488762

JX488763

JX488764

JX488765

JX488766

JX488767

JX488768

JX488769

JX488835

TU 124.06

UAIC 11371.01

UNL 1-30

NC008645

AF454868

JX488837

KF929801

JX488770

JX488838

\section{USU-UBL}

USU-USD

BRK0507-2

JEB0504-2

JEB0505-7

JEB0510-1

BRK0511-6

$\begin{array}{lll}\text { JX488771 } & \text { JX488839 } & \text { JN024886 } \\ \text { JX488772 } & \mathbf{J X 4 8 8 8 4 0} & - \\ \mathbf{J X 4 8 8 7 7 3} & \mathbf{J X 4 8 8 8 4 1} & \text { EU668462 } \\ \mathbf{J X 4 8 8 7 7 4} & \mathbf{J X 4 8 8 8 4 2} & - \\ \mathbf{J X 4 8 8 7 7 5} & \mathbf{J X 4 8 8 8 4 3} & - \\ \mathbf{J X 4 8 8 7 7 6} & \mathbf{J X 4 8 8 8 4 4} & - \\ \mathbf{J X 4 8 8 7 7 7} & \mathbf{J X 4 8 8 8 4 5} & \text { EU668375 }\end{array}$

JX488948

JX488949

JX488950

JX488951

JX488952

JX488953

JX488954
JF837387

GU937849

JF837435

JF799533

$-$

$-$

GU937840

FJ226251

$-$

FJ265028 


\begin{tabular}{|c|c|c|c|c|c|c|c|}
\hline C. cahita 2 & BRK0511-8 & JX488778 & JX488846 & - & JX488955 & This study & - \\
\hline C. catostomus & - & - & - & W.J. Chen & W.J. Chen & - & - \\
\hline C. catostomus & UAIC 11237.04 & AF454871 & JX488847 & EU523925 & - & - & GU937824 \\
\hline C. columbianus & OS 17548 & JX488780 & JX488849 & - & JX488957 & - & - \\
\hline C. commersoni 1 & - & NC008647 & NC008647 & - & - & This study & - \\
\hline C. commersoni 2 & UAIC 11156.03 & JX488781 & JX488850 & EU523931 & JX488958 & This study & JF799535 \\
\hline C. fumeiventris 1 & - & JX488784 & JX488853 & - & JX488961 & - & - \\
\hline C. fumeiventris 2 & - & JX488785 & JX488854 & - & JX488962 & - & - \\
\hline C. insignis & MSB 49603-2 & JX488786 & JX488855 & - & JX488963 & - & - \\
\hline C. insignis & MSB 49603-4 & JX488787 & JX488856 & HQ556974 & JX488964 & This study & - \\
\hline C. latipinnis 1 & MSB 49601 & JX488788 & JX488857 & - & JX488965 & This study & - \\
\hline C. latipinnis 2 & MSB 49602 & JX488789 & JX488858 & - & JX488966 & - & - \\
\hline C. leopoldi & JEB15-1 & JX488790 & JX488859 & EU668394 & JX488967 & - & - \\
\hline C. macrocheilus & OS 15886 & JX488791 & JX488860 & EU523932 & JX488968 & - & - \\
\hline C. microps & OS 17571-1 & JX488792 & JX488861 & HQ557219 & JX488969 & This study & - \\
\hline C. microps & OS 17571-2 & JX488793 & JX488862 & - & JX488970 & - & - \\
\hline C. occidentalis humboldtianus 1 & OS $15623-1$ & JX488795 & JX488864 & - & JX488972 & - & - \\
\hline C. occidentalis humboldtianus 2 & OS $15623-2$ & JX488796 & JX488865 & - & JX488973 & - & - \\
\hline C. occidentalis lacusanserinus & OS 1943BB & JX488797 & JX488866 & - & JX488974 & - & - \\
\hline C. occidentalis mniotiltus 1 & UAIC $13448.01-2$ & JX488798 & $J X 488867$ & - & JX488975 & - & - \\
\hline C. occidentalis mniotiltus 2 & UAIC 13448.01-4 & JX488799 & JX488868 & - & JX488976 & - & - \\
\hline C. occidentalis occidentalis & UAIC 11546.02-1 & JX488800 & JX488869 & KF558280 & JX488977 & This study & - \\
\hline C. rimiculus & OS 15908 & AF454875 & JX488874 & - & JX488982 & - & - \\
\hline C. snyderi & OS 15900 & JX488806 & JX488876 & - & JX488984 & - & - \\
\hline
\end{tabular}




\begin{tabular}{|c|c|c|c|c|c|c|c|}
\hline C. tahoensis 1 & BuffaloCrk4 & JX488807 & JX488877 & JN024954 & JX488985 & This study & - \\
\hline C. tahoensis 2 & SmokeCrk1 & JX488808 & JX488878 & - & JX488986 & - & - \\
\hline C. tsiltcoosensis 1 & OS X113 & JX488809 & JX488879 & - & JX488987 & - & - \\
\hline C. tsiltcoosensis 2 & OS X114 & JX488810 & JX488880 & - & JX488988 & - & - \\
\hline C. warnerensis 1 & OS $14251-2$ & JX488814 & JX488884 & - & JX488992 & This study & - \\
\hline C. warnerensis 2 & OS $14251-3$ & JX488815 & JX488885 & - & JX488993 & - & - \\
\hline C. wigginsi & JEB0511-1 & JX488816 & JX488886 & EU668440 & JX488994 & - & - \\
\hline Catostomus sp. Coquille River & OS X130 & JX488811 & JX488881 & - & JX488989 & - & - \\
\hline Catostomus sp. Wall Canyon 1 & OS X61 & JX488812 & JX488882 & - & JX488990 & - & - \\
\hline Catostomus sp. Wall Canyon 2 & OS X67 & JX488813 & JX488883 & - & JX488991 & - & - \\
\hline Chasmistes brevirostris & OS 15963 & JX488817 & JX488887 & - & JX488995 & - & GU937825 \\
\hline Ch. liorus mictus 1 & BYU 56945 & JX488818 & JX488888 & - & JX488996 & - & - \\
\hline Ch. liorus mictus 2 & BYU 56946 & JX488819 & JX488889 & - & JX488997 & - & - \\
\hline Deltistes luxatus & OS 15922 & AF454870 & JX488890 & - & JX488998 & - & GU937831 \\
\hline Pantosteus clarkii & MSB 49600 & JX488779 & JX488848 & HQ556940 & JX488956 & - & - \\
\hline P. discobolus discobolus & BYU 57986 & JX488782 & JX488851 & - & JX488959 & - & GU937830 \\
\hline P. discobolus yarrowi & UAIC 12776.01-2 & JX488783 & JX488852 & - & JX488960 & - & - \\
\hline P. nebuliferus & HLB1484 & JX488794 & JX488863 & EU668538 & JX488971 & - & - \\
\hline P. platyrhynchus 1 & BYU 58618 & JX488801 & JX488870 & EU523934 & JX488978 & - & - \\
\hline P. platyrhynchus 2 & BYU 58621 & JX488802 & JX488871 & - & JX488979 & - & - \\
\hline P. plebeius 1 & DAN0521-10 & JX488803 & JX488872 & EU668409 & JX488980 & - & GU937833 \\
\hline P. plebeius 2 & DAN0526-01 & JX488804 & JX488873 & - & JX488981 & - & - \\
\hline P. santaanae & UAIC 12384.01 & JX488805 & JX488875 & JN024948 & JX488983 & - & - \\
\hline Xyrauchen texanus 1 & OS X97 & JX488824 & JX488935 & HQ556969 & JX489042 & This study & - \\
\hline
\end{tabular}


X. texanus 2

Tribe Erimyzonini

Erimyzon oblongus 1

Erimyzon oblongus 2

E. sucetta 1

E. sucetta 2

\section{E. tenuis}

Minytrema melanops 1

Minytrema melanops 2

Minytrema melanops 3

Minytrema melanops 4

Tribe Moxostomatini

Moxostoma albidum 1

M. albidum 2

M. anisurum

M. ariommum

M. austrinum

$M$. sp. cf. austrinum

M. breviceps

M. carinatum 1

M. carinatum 2

M. cervinum

M. collapsum 1

M. collapsum 2
OS X98

UAIC 11109.09

BRK05-52

UAIC 12286.01

C306

UAIC 12370.04

$-$

$$
-
$$

UAIC 11141.01

BRK056

UAIC 12365.01

UAIC 13446.01

UAIC 11606.02

UAIC 12071.01

UAIC 12375.01

UAIC 12373.01

UAIC 11314.08

UAIC 11005.03

PBB0023

UAIC 11004.01

UAIC 11007.03

UAIC 12376.05

\section{JX488825 JX488936}

AF454876 $-$

AF45478

$-$

AF454877

AB242116

DQ536432

AF454879

$-$

AF454902

JX488898

EU751969

JX488900 EU524146

AF454903

JX488901

JN027267

AF454898 JX488902

AF454904 JX488903

AF454888

JX488904

AF454883

JX488905

JX488820 JX488906

AF454906

JX488907

AF454882

JX488908

AF454881

JX488909
$-$

JN027271

EU524147 $-$

JN027274

JN027276

$-$
JX489043

$-$

This study -

JX488999

$-$

GU937837

$\mathrm{X} 489000$

JX489001

$-$

$-$

JX489005

JX489006

JX489007

JX489008

JX489009

JX489010

JX489011

JX489012

JX489013

JX489014

JX489015

JX489016

JX489017
This study GU937838

$-$

FJ265050

- $\quad-$

$-$

$-$

This study JF799563

This study -

This study JF799537

This study JF799557

This study JF799565

This study JF799564

This study JF799542

This study JF799547

This study -

This study JF799556

This study -

This study - 


\begin{tabular}{|c|c|c|c|c|c|c|c|}
\hline M. congestum 1 & UAIC 13506.05 & AF522290 & JX488910 & JN027282 & JX489018 & This study & JF799560 \\
\hline M. congestum 2 & UAIC 13508.05 & AF522291 & JX488911 & - & JX489019 & This study & - \\
\hline M. congestum 3 & UAIC 13512.05 & AF522292 & JX488912 & - & JX489020 & This study & - \\
\hline M. duquesnei 1 & UAIC 11310.09 & AF454894 & JX488913 & EU524861 & - & - & - \\
\hline M. duquesnei 2 & JFBM38581 & AF454895 & JX488914 & - & JX489021 & This study & JF799554 \\
\hline M. erythrurum 1 & UAIC 12237.03 & AF454886 & JX488915 & EU524867 & JX489022 & This study & JF799551 \\
\hline M. erythrurum 2 & JFBM37043 & AF454887 & JX488916 & - & JX489023 & This study & - \\
\hline M. hubbsi 1 & NCSM 36440 & AF522289 & JX488917 & EU524877 & JX489024 & This study & JF799544 \\
\hline M. hubbsi 2 & 06-19 & JX488821 & JX488918 & - & JX489025 & This study & - \\
\hline M. lachneri & UAIC 12370.02 & AF454900 & JX488919 & JN027292 & JX489026 & This study & JF799559 \\
\hline M. sp. cf. lachneri & UAIC 12462.03 & AF454907 & JX488920 & - & JX489027 & This study & - \\
\hline M. macrolepidotum & UAIC 11221.10 & AF454890 & JX488921 & EU524149 & JX489028 & This study & JF799539 \\
\hline M. sp. cf. macrolepidotum & UAIC 11643.01 & AF454885 & JX488922 & - & JX489029 & This study & F799541 \\
\hline M. mascotae & UAIC 12374.01 & AF454899 & JX488923 & - & JX489030 & This study & JF7995666 \\
\hline M. pappillosum & UAIC 13462.01 & AF454883 & JX488924 & JN027303 & JX489031 & This study & JF799538 \\
\hline M. poecilurum 1 & - & NC008674 & NC008674 & - & - & - & - \\
\hline M. poecilurum 2 & UAIC 11442.01 & AF454896 & JX488925 & HQ579038 & JX489032 & This study & JF799552 \\
\hline M. sp. cf. poecilurum & UAIC 12746.13 & AF454897 & JX488926 & - & JX489033 & This study & - \\
\hline M. pisolabrum & UAIC 11154.05 & AF454889 & JX488927 & HQ557206 & JX489034 & This study & - \\
\hline M. robustum & UAIC 11916.01 & AF454891 & JX488928 & JN027313 & JX489035 & This study & JF799546 \\
\hline M. rupiscartes & UAIC 12376.06 & AF454905 & JX488929 & JN027315 & JX489036 & This study & JF799558 \\
\hline M. valenciennesi & JFBM36305 & AF454893 & JX488930 & EU524150 & JX489037 & This study & JF799543 \\
\hline \multicolumn{8}{|l|}{ be Thoburniini } \\
\hline Hypentelium etowanum & UAIC 12523.08 & AF454908 & JX488894 & JN026830 & JX489002 & - & GU937836 \\
\hline
\end{tabular}




\begin{tabular}{|c|c|c|c|c|c|c|c|}
\hline H. nigricans 1 & - & NC008676 & NC008676 & - & - & - & - \\
\hline H. nigricans 2 & UAIC 11138.02 & AF454909 & JX488895 & EU524667 & JX489003 & This study & JF799571 \\
\hline H. roanokense & UAIC 13449.02 & AF454910 & JX488896 & JN026848 & JX489004 & This study & JF799570 \\
\hline Thoburnia atripinnis & UAIC 13463.01 & AF454911 & JX488931 & HQ937020 & JX489038 & This study & JF799569 \\
\hline T. hamiltoni 1 & NCSM 45840-1 & JX488822 & JX488932 & - & JX489039 & - & JF799567 \\
\hline T. hamiltoni 2 & NCSM 45840-3 & JX488823 & JX488933 & - & JX489040 & This study & - \\
\hline T. rhothoeca & UAIC 11009.05 & AF454912 & JX488934 & JN028432 & JX489041 & This study & JF799568 \\
\hline
\end{tabular}




\section{Table 3(on next page)}

Characteristics of each of the seven morphological and molecular datasets analyzed in this study.

Data subsets: $1=$ mtDNA $1^{\text {st }}$ codon sites; $2=$ mtDNA $2^{\text {nd }}$ codon sites; $3=$ mtDNA $3^{\text {rd }}$ codon sites; $4=\operatorname{IRBP}$ $1^{\text {st }}$ codon sites; $5=$ IRBP $2^{\text {nd }}$ codon sites; $6=$ IRBP $3^{\text {rd }}$ codon sites; $7=\mathrm{GHI}+$ RPS7 sites, combined; $\mathrm{M}=$ morphological characters; ' + ' symbols indicate that a given subset was included in the dataset while ' - ' symbols indicate it was not.

${ }^{\dagger}$ During BEAST analyses, but not MrBayes analyses, morphological characters were subdivided into various subsets described in the text and Mendeley-deposited input files. 
Data subsets

\begin{tabular}{|c|c|c|c|c|c|c|c|c|c|c|c|}
\hline \multirow[b]{2}{*}{ Dataset } & \multirow[b]{2}{*}{$\begin{array}{l}n \text { (no. } \\
\text { ingroup tips) }\end{array}$} & \multirow{2}{*}{$\begin{array}{l}\text { No. characters } \\
\text { (missing data \% } \\
\text { of total) }\end{array}$} & \multirow{2}{*}{$\begin{array}{l}\text { No. parsimony } \\
\text { informative } \\
\text { characters (\% total) }\end{array}$} & \multicolumn{8}{|c|}{ Data subsets } \\
\hline & & & & 1 & 2 & 3 & 4 & 5 & 6 & 7 & ${ }^{\dagger} \mathbf{M}$ \\
\hline concatenated mtDNA & $126(121)$ & 2836 bp $(11.9 \%)$ & $1216(42.9 \%)$ & + & + & + & - & - & - & - & - \\
\hline four-locus & $85(80)$ & 5925 bp $(23.1 \%)$ & $1893(31.9 \%)$ & + & + & + & + & + & + & + & - \\
\hline morphology & $64(62)$ & $123(11.7)$ & $120(97.6 \%)$ & - & - & - & - & - & - & - & + \\
\hline mtDNA + morphology & $85(80)$ & $2959(11.9 \%)$ & $1336(45.2 \%)$ & + & + & + & - & - & - & - & + \\
\hline total-evidence & $85(80)$ & $6048(23.3 \%)$ & $2013(33.3 \%)$ & + & + & + & + & + & + & + & + \\
\hline nuclear IRBP & $113(108)$ & 839 bp $(0.3 \%)$ & $210(25.0 \%)$ & - & - & - & + & + & + & - & - \\
\hline concatenated nDNA & $113(108)$ & 3089 bp $(36.4 \%)$ & $677(21.9 \%)$ & - & - & - & + & + & + & + & - \\
\hline
\end{tabular}




\section{Table 4(on next page)}

Bayes factor tests comparing twelve Bayesian relaxed-clock partitioning models applied to the total-evidence dataset.

Models including only $3^{\text {rd }}$ codon sites of the mtDNA matrix were ruled out, because those sites had the highest amounts of predicted homoplasy during PI profiling (Results and Discussion, Fig. 5), and excluding them yielded the single greatest improvement in logmarginal likelihoods (e.g. $M_{1}$ versus $M_{4}$ ). Numbers and letters in brackets correspond to data subsets defined in the text and Table 3. Log-marginal likelihood estimates were derived from path sampling, and Bayes factors were estimated for each model when compared against the best-supported model. 


\begin{tabular}{|c|c|c|c|c|c|c|}
\hline Model & Mitochondrial DNA & $\begin{array}{l}\text { Problematic } \\
\text { sites (\#) }\end{array}$ & $\begin{array}{l}\text { Relaxed } \\
\text { clocks (\#) }\end{array}$ & Clock-partitioning & $\begin{array}{l}\text { Log-marginal } \\
\text { likelihood }\end{array}$ & $\begin{array}{l}2 \log _{e}\left(B_{10}\right) \\
\text { Bayes } \\
\text { factor }\end{array}$ \\
\hline$M_{1}$ & $\begin{array}{l}1^{\text {st }}, 2^{\text {nd }}, \text { and } 3^{\text {rd }} \text { codon } \\
\text { sites }\end{array}$ & 2 & 1 & {$[1,2,3,4,5,6,7, \mathrm{M}]$} & -69461.62 & -89832.36 \\
\hline$M_{2}$ & $\begin{array}{l}1^{\text {st }}, 2^{\text {nd }} \text {, and } 3^{\text {rd }} \text { codon } \\
\text { sites }\end{array}$ & 2 & 2 & {$[1,2,3,4,5,6,7][\mathrm{M}]$} & -69078.47 & -89066.05 \\
\hline$M_{3}$ & $\begin{array}{l}1^{\text {st }}, 2^{\text {nd }} \text {, and } 3^{\text {rd }} \text { codon } \\
\text { sites }\end{array}$ & 2 & 8 & [1] [2] [3] [4] [5] [6] [7] [M] & -67222.91 & -85354.94 \\
\hline$M_{4}$ & $1^{\text {st }}+2^{\text {nd }}$ codon sites & 1 & 1 & {$[1,2,4,5,6,7, M]$} & -38876.51 & -28662.13 \\
\hline$M_{5}$ & $1^{\text {st }}+2^{\text {nd }}$ codon sites & 1 & 2 & {$[1,2,4,5,6,7][\mathrm{M}]$} & -38385.92 & -27680.96 \\
\hline$M_{6}$ & $1^{\text {st }}+2^{\text {nd }}$ codon sites & 1 & 7 & {$[1][2][4][5][6][7][\mathrm{M}]$} & -37616.86 & -26142.84 \\
\hline$M_{7}$ & $1^{\text {st }}$ codon sites & 1 & 1 & {$[1,4,5,6,7, \mathrm{M}]$} & -34866.49 & -20625.92 \\
\hline$M_{8}$ & $1^{\text {st }}$ codon sites & 1 & 2 & {$[1,4,5,6,7][\mathrm{M}]$} & -34382.43 & -19673.97 \\
\hline$M_{9}$ & $1^{\text {st }}$ codon sites & 1 & 6 & [1] [4] [5] [6] [7] [M] & -33682.60 & -18237.36 \\
\hline$M_{10}$ & $2^{\text {nd }}$ codon sites & 0 & 1 & {$[2,4,5,6,7, \mathrm{M}]$} & -25442.32 & -1793.75 \\
\hline$M_{11}$ & $2^{\text {nd }}$ codon sites & 0 & 2 & {$[2,4,5,6,7][\mathrm{M}]$} & -25138.71 & -1186.53 \\
\hline$M_{12}$ & $2^{\text {nd }}$ codon sites & 0 & 6 & [2] [4] [5] [6] [7] [M] & -24545.44 & 0 \\
\hline
\end{tabular}




\section{Figure 1 (on next page)}

Six alternative hypotheses of phylogenetic relationships among Catostomidae subfamilies and tribes.

These results were based on previous studies of electrophoretic data (A); morphological, behavioral, and developmental characters (B); and DNA sequence data (C-F). 


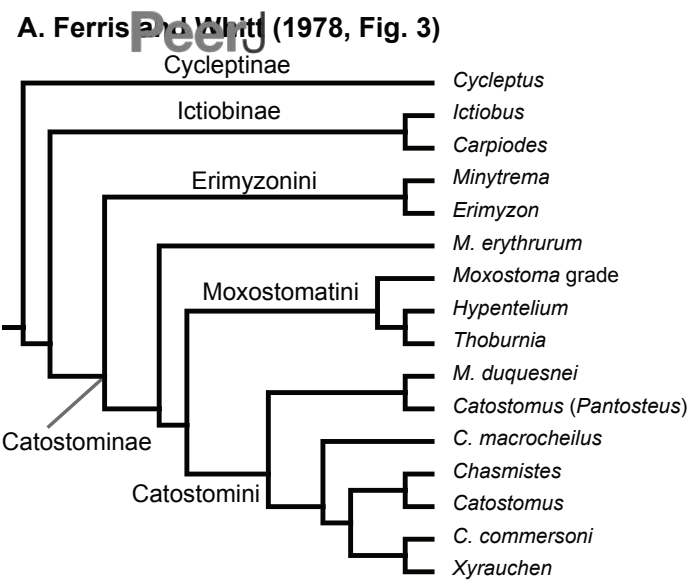

C. Harris and Mayden (2001, Fig. 5)

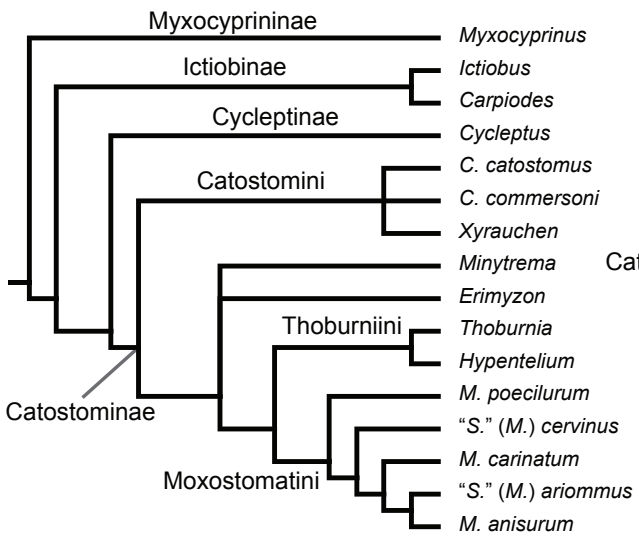

E. Sun et al. (2007, Fig. 1)

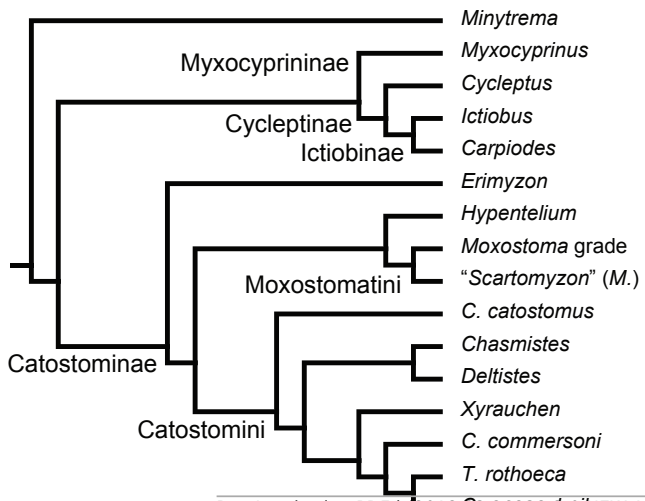

PeerJ reviewing PDF |
B. Smith (1992, Fig 6$)$ pt to be reviewed

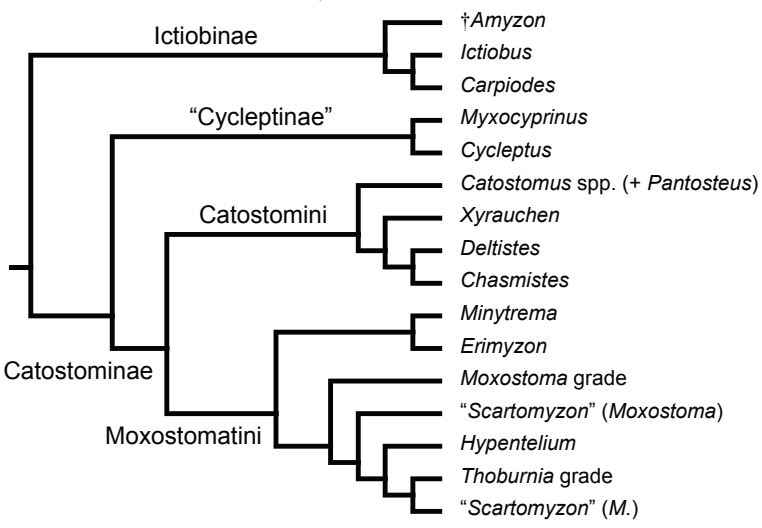

D. Harris et al. (2002, Fig. 4)

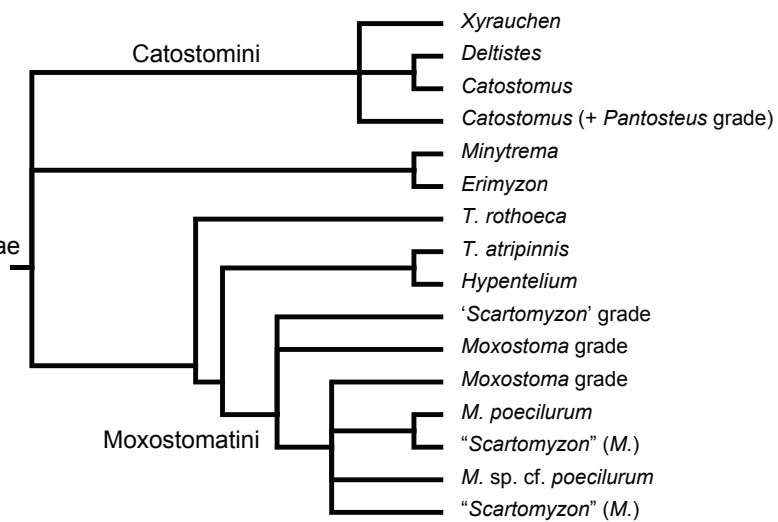

F. Doosey et al. (2010, Fig. 1)

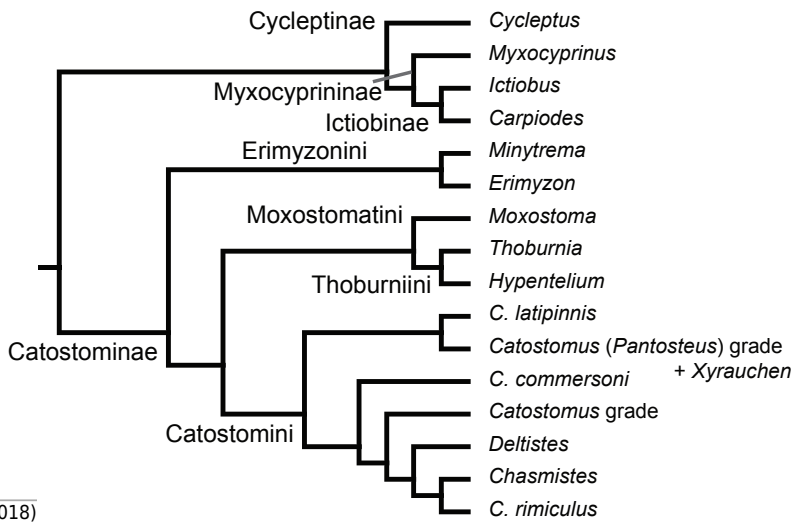




\section{Figure 2 (on next page)}

Consensus topologies from MrBayes (Ronquist et al., 2012) analyses of the concatenated mtDNA (A), four-locus (B), morphology (C), mtDNA + morphology (D), total-evidence $(\mathrm{E})$, concatenated $\mathrm{nDNA}(\mathrm{F})$, and nuclear IRBP $(\mathrm{G})$ datasets.

Subfamily and tribe names and colors shown in panel A are followed throughout; in panels B-G, text labels highlight positions of different taxa, including subfamilies (Myx., Myxocyprininae), tribe Catostomini, and Pantosteus, and dagger symbols indicate extinct taxa. Filled black circles indicate nodes with significant Bayesian posterior probabilities (BPP $\geq 0.95$ ), and gray circles indicate near-significant nodes (BPP $=0.80-0.94$ ). Scale bars are given in units of substitutions/site. 


\section{A. concatenated mtDNA}

Catostomini (genus

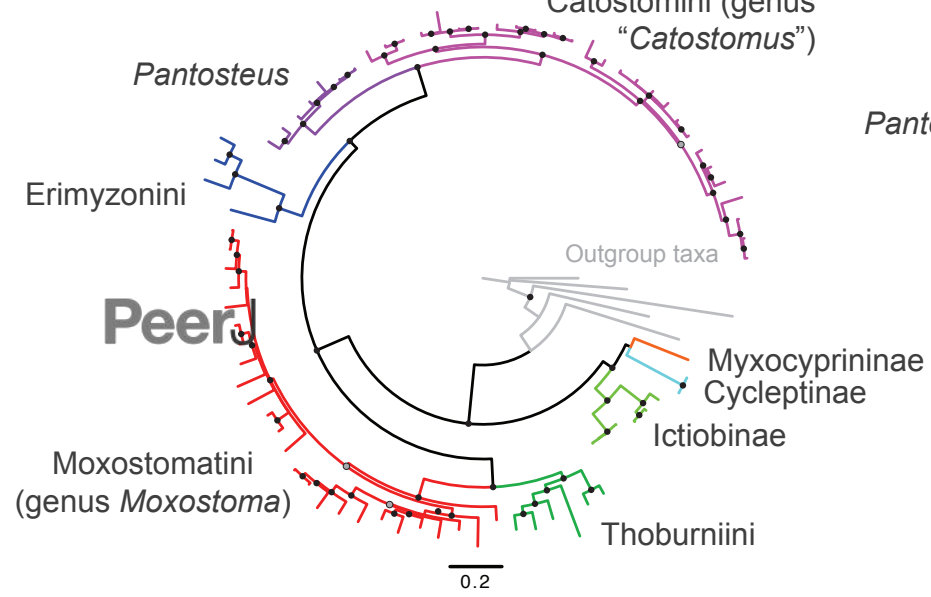

C. morphology

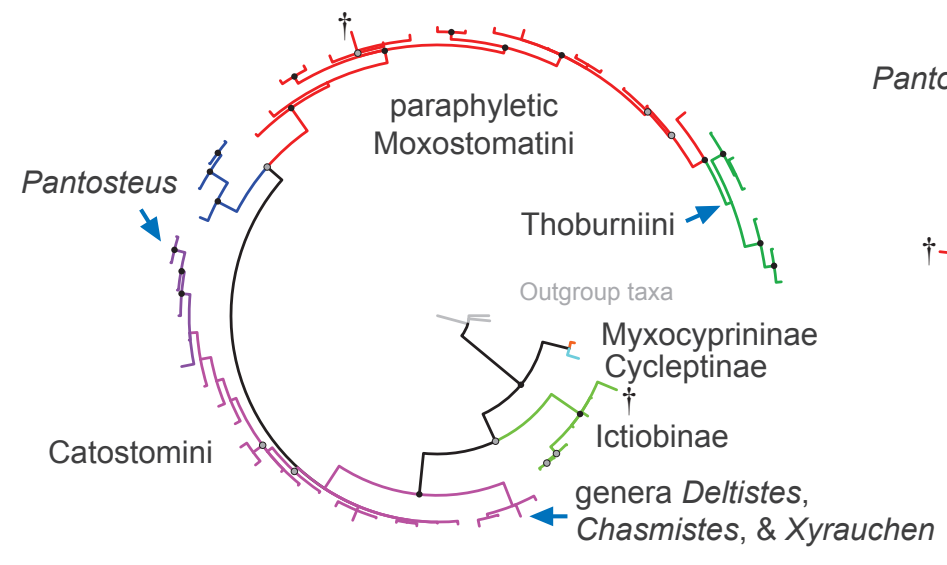

$\overline{0.4}$

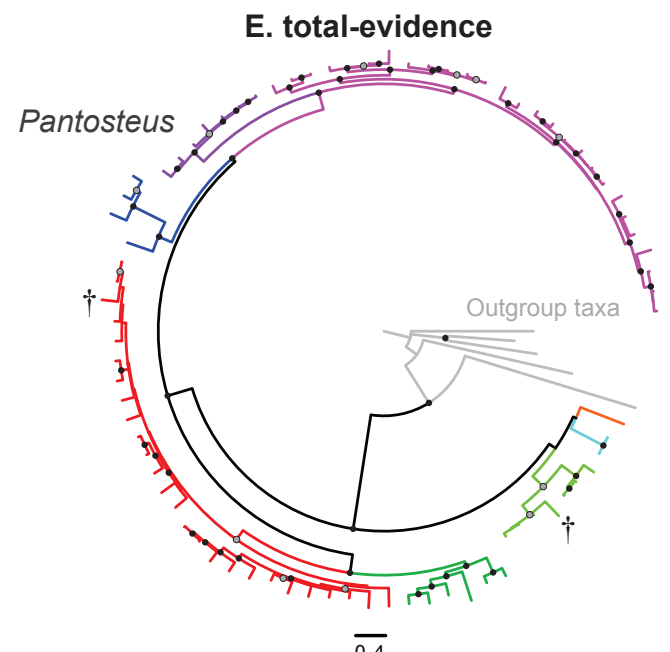

G. concatenated

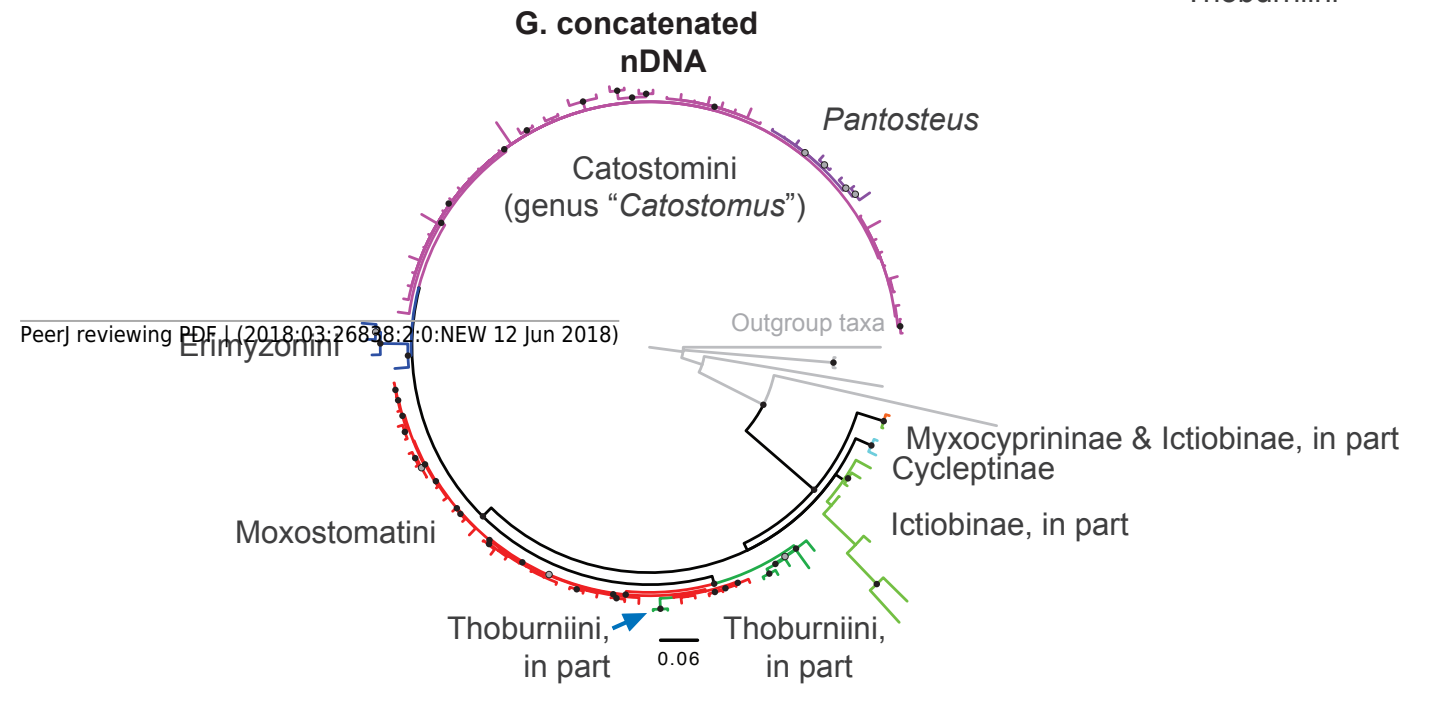

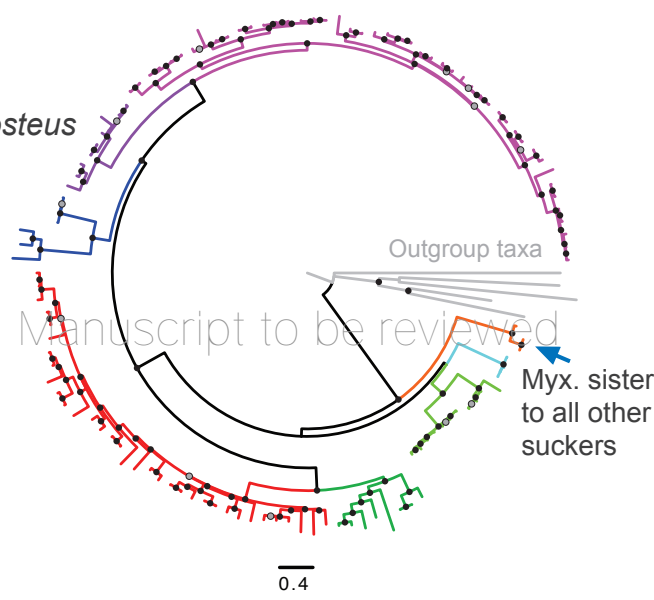

D. mtDNA + morphology

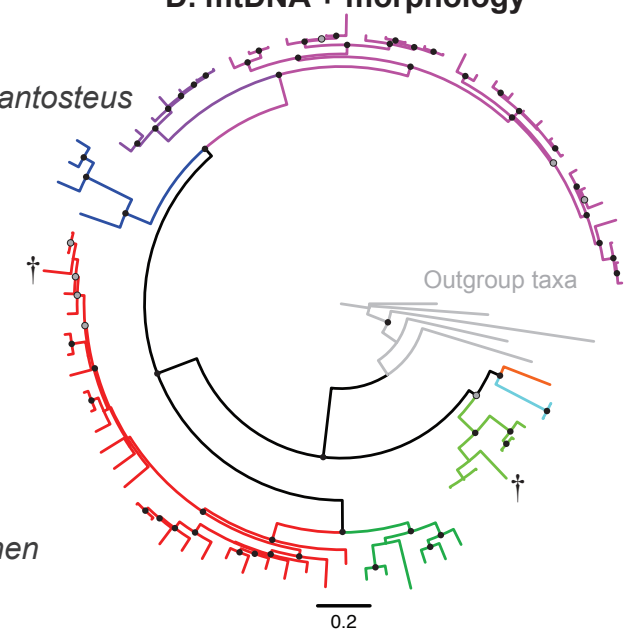

F. nuclear IRBP

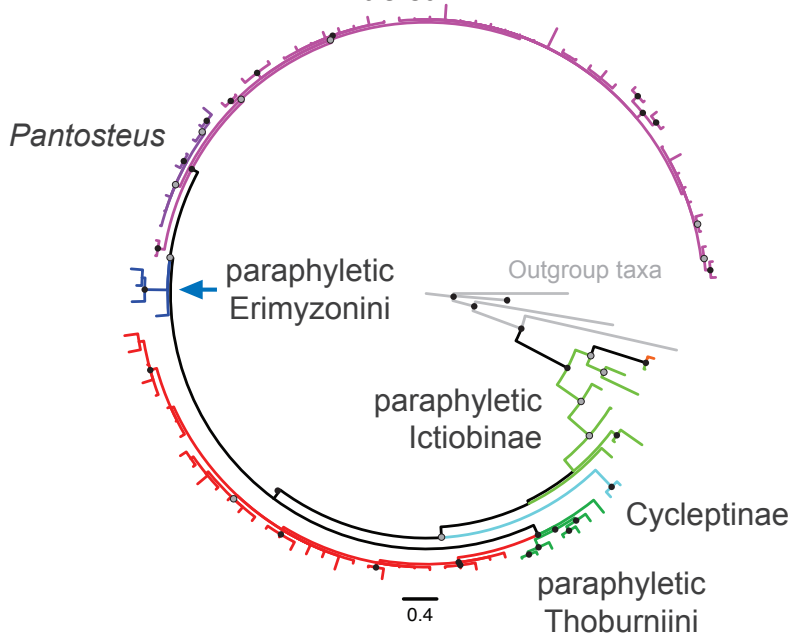


Figure 3 (on next page)

Phylogeny of suckers inferred from Bayesian analysis of the combined mtDNA (cytb, cox1, ND2), nDNA (IRBP, GHI, and RPS7), and morphological data (123 characters) in the total-evidence dataset.

Within tip labels, dagger symbols indicate extinct taxa, and museum (voucher) or field numbers are followed by the number of the individual sequenced (Table 1). Nodes are labeled with Bayesian posterior probability support values above 0.50 . Scale bars are in units of substitutions/site. 


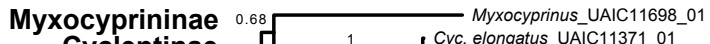
Cycleptinae Myxocyprinus

Cycleptus ReerJ 0.69

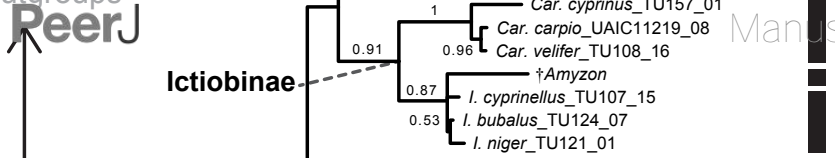

Caripiotodes

\section{$\dagger$ Amyzon \\ Ictiobus}

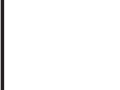

Thoburniini $1-$ T. hamiltoni_NCSM45840_3

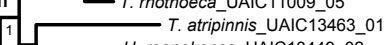

H. roanokense_UAIC13449_02

1 H. etowanum_UAIC12523_08

\section{Catostomidae} (1)

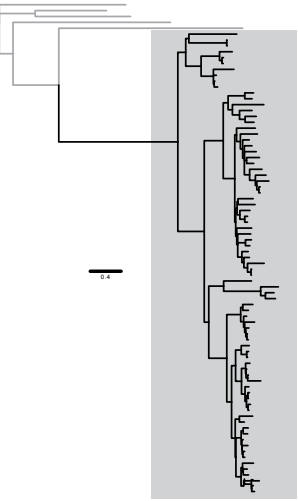

\section{Catostominae}
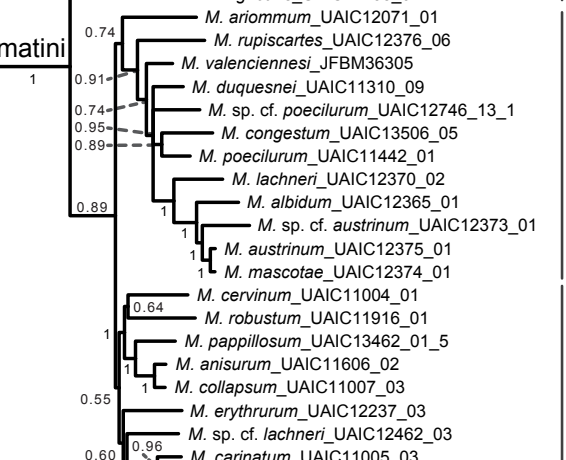

Clade 2

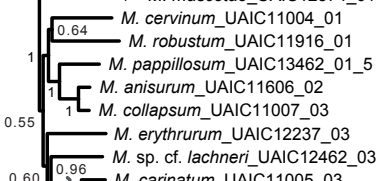

$0 . 6 0 \longdiv { 0 . 9 6 }$ M. carinatum UAIC11005 03

0.64 L $M$. sp. cf. macrolepidotum_UAIC11643_01_1

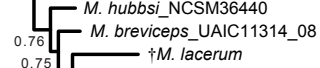

$0 . 7 5 \longdiv { M } +$ lacerum

_ Min. melanops_1

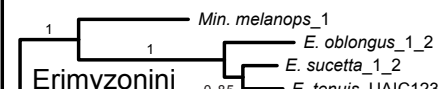
P. nebuliferus

- P. plebeius_DAN0521_10

[ P. platyrhynchus_BYU58618

0.86 P P. santaanae_UAIC12384_01

- P. clarkii_MSB49600

P. discobolus_BYU57986

0.97 P. discobolus yarrowi_UAIC12776_01_2

1 C. fumeiventris_1

1 C C. sp. Wall Canyon_OSX61

C. sp. Wall

0.91 C. warnerensis_OS1425

Catostomini

6-a

1 i C. snyderi_OS15900

Ch. brevirostris_OS15963

1 D. luxatus_OS15922

[ C. occ. humoldtianus_OS15623_1

1 C. microps_OS17571_1

1 C. occ. lacusanserinus_OS1943BB 6-c

0.83 C. occ. mniotiltus_UAIC13448_01_2

0.91 C. occ. occidentalis_UAIC11546_02_1

$1 \sqrt[1]{- \text { C. commersoni_UAIC11156_03 }}$

C. ardens_USU_UBL

1 - C. ardens_liorus mictus_BYU56945

Clade 1

hoburnia

Hypentelium

Moxostoma

Clade 3

Clade 4

Minytrema

Erimyzon

Clade 5

Pantosteus

$0.55--1$ C. macrocheilus_OS 15886

0.71

C. tsiltcoosensis_OSX113

X.96.- texanus_OSX97

PeerJ reviewing PDF | (2018:03:26838:2:0:NEW $9 \cdot \overline{1}$ Juntopis) C. latipinnis_MSB49601

| Clade 7

"Catostomus"

Clade 8 


\section{Figure 4 (on next page)}

Time-calibrated phylogeny of Catostomidae derived from the best-supported Bayesian total-evidence dating model identified in Table 4.

In parentheses beside subfamily and tribe names, numbers of extinct or fossil tips are presented out of total sample size for the corresponding clade. Along nodes, filled black circles indicate significant posterior support (BPP $\geq 0.95$ ), gray circles indicate near-significant support (BPP $=0.80-0.94$ ), and horizontal node bars show $95 \%$ highest posterior densities of age estimates. The inset table shows Bayesian posterior age estimates given as mean $t_{\text {MRс }} \mathrm{S}$, with their 95\% highest posterior densities (HPDs; credible intervals), in units of millions of years ago (Ma). Geological epoch abbreviations: Paleo., Paleocene; Oligo., Oligocene; Q., Quaternary; Pl., Pliocene; P., Pleistocene. 
Figure 5 (on next page)

Phylogenetic informativeness of the sucker datasets.

(A) BEAST chronogram from Fig. 4 used for site rate calculations, showing the three main subfamilies with incongruent relationships highlighted in red. Phylogenetic informativeness profiles matched to the chronogram time scale are shown for seven subsets of the four-locus dataset (B), and for the morphology dataset (C). Colored shading in (B) and (C) indicate areas integrated below each profile over the 'subfamily divergence epoch' ( 63.2-34.4 Ma) containing branching relationships among the four subfamilies. 


\section{PeerJ}

'subfamily divergence epoch'
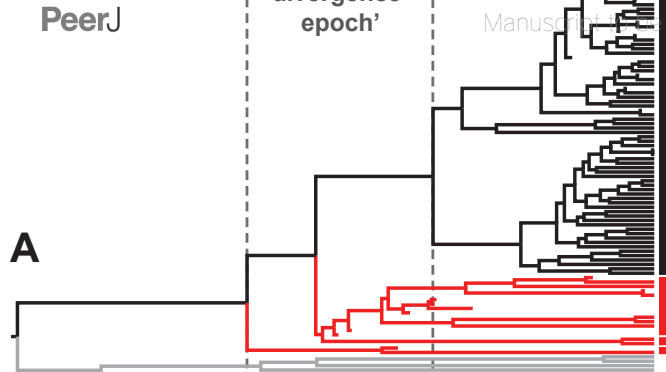

- Catostominae

100

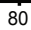

i 60

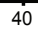

I

mtDNA 1st codon pos.

mtDNA 2nd codon pos.

mtDNA 3rd codon pos.

IRBP 1st codon pos.

IRBP 2nd codon pos.

IRBP 3rd codon pos.

GHI + RPS7

B 